Finance and Economics Discussion Series Divisions of Research \& Statistics and Monetary Affairs Federal Reserve Board, Washington, D.C.

\title{
From the Horse's Mouth: Gauging Conditional expected Stock returns from Investor Survey
}

\section{Gene Amromin and Steven A. Sharpe}

2005-26

NOTE: Staff working papers in the Finance and Economics Discussion Series (FEDS) are preliminary materials circulated to stimulate discussion and critical comment. The analysis and conclusions set forth are those of the authors and do not indicate concurrence by other members of the research staff or the Board of Governors. References in publications to the Finance and Economics Discussion Series (other than acknowledgement) should be cleared with the author(s) to protect the tentative character of these papers. 


\title{
From the horse's mouth: \\ Gauging conditional expected stock returns from investor surveys
}

\author{
Gene Amromin and Steven A. Sharpe* \\ Federal Reserve Board \\ Washington, D.C.
}

April 2005

\begin{abstract}
We use data obtained from a series of Michigan Surveys of Consumer Attitudes to study stock market beliefs and portfolio choices of individual investors. We find that expected returns over the medium- and long-term horizon appear to be extrapolated from past realized returns. The findings also indicate that a more optimistic assessment of macroeconomic conditions coincides with higher expected returns and lower expected volatility, implying strongly procyclical Sharpe ratios. These results are given added credence by the empirical finding that reported portfolio concentrations in equities tend to be higher for respondents who anticipate higher returns and lower uncertainty. Overall, our empirical results lend support to the hypothesis that equity valuations are lower during recessions - and subsequent returns are higher - because of undue pessimism about future returns, rather than high risk aversion.

\footnotetext{
*The authors thank Joshua Schwartzstein and Daniel Rawner for outstanding research assistance. We also thank, seminar participants at the Federal Reserve Board, the Chicago Fed, the University of Minnesota, and the Wharton Conference on Household Portfolio Choice and Decision-Making for their comments. All remaining errors are our own. The views expressed in this paper are solely the responsibility of the authors and should not be interpreted as reflecting the views of the Board of Governors of the Federal Reserve System or of any other employee of the
} without implicating, Sean Campbell, Matt Pritsker, David Laibson, David Marshall, Paul Seguin, Justin Wolfers and Federal Reserve System. Email addresses for the authors are gene.amromin@,frb.gov and steve.a.sharpe@,frb.gov.
\end{abstract}




\section{Introduction}

Despite a vast body of research, considerable disagreement remains regarding the level and dynamics of expected stock returns and the equity premium. The traditional and most prevalent approach relies heavily upon the use of realized returns as noisy estimates of expected returns. In turn, time variation in expected returns - the stochastic discount factor - is inferred by regressing these realized returns on ex ante observable conditioning variables. ${ }^{1}$ The potential weaknesses of using realized returns have received increased attention of late, particularly in light of the growing consensus that expected returns on stocks are subject to sizable fluctuations. As Fama and French (2002) and others (most recently, e.g., Campello, et al. 2004) argue, timevariation in expected returns works against the convergence of average realized return to expected return. For instance, when required returns rise, stock prices generally decline as a result, causing actual measured returns to be low. As a consequence, realized returns can be a quite misleading measure of expected returns.

Recent studies have proposed a variety of alternative methods that do not use actual returns in the estimation of expected returns. The newer methodologies mostly rely on ex ante forecasts of fundamentals, which, in conjunction with the level of stock prices or dividend yields, can be used to construct ex ante estimates of expected long-run returns. Fama and French (2002) obtain estimates of expected market returns over the past half-century using macroeconomic forecasts of earnings and dividends. Several other studies, such as Claus and Thomas (2001) and Gebhardt, Lee and Swaminathan (2001), construct estimates of expected returns using analysts' earnings forecasts and the concurrent level of stock prices. Campello, Chen, and Zhang (2004) infer expected stock returns from estimates of expected returns on bonds, which are in turn constructed from prevailing yield spreads and forecasts of default rates.

\footnotetext{
${ }^{1}$ Some classic studies in this vein are Chen, Roll, and Ross (1986) and Fama and French (1989). Among the more recent studies that fall into this category are Lettau and Ludvigson (2001) and Goyal and Welch (2002).
} 
Our study attempts to measure expected equity returns directly, by analyzing survey responses of individual household investors. Our survey data is extracted from a special section of questions drawn up for the Michigan Survey of Consumer Attitudes, which has been run about four times per year, on average, between September 2000 and October 2004. These questions solicit views about the likely future performance of both the stock market and the respondent's own portfolio. In addition, the survey elicits information on investors' perceptions regarding risk in stock market returns, as well as data on the amount of equities in their investment portfolio. Unlike other survey-based studies of investor expectations, our data on stock market expectations comes with a rich array of complementary survey data on respondent perceptions of macroeconomic conditions and their own circumstances, which is incorporated into our analysis.

Our study comes on the heels of a recent spate of survey-based studies of expected stock market returns, each of which has provided useful clues about the behavior of the equity premium (see, for example Welch, 2000; Fraser, 2001; Brav, Lehavy, and Michaely, 2003). Two survey-based studies that are closer in spirit to our analysis are Vissing-Jorgensen (2003) and Graham and Harvey (2003). Vissing-Jorgensen (2003) analyzes the survey responses of retail mutual fund investors and finds evidence of cognitive biases, though less so among wealthy respondents. For instance, wealthier investors appear to suffer less from biased selfattribution (Daniel, Hirshleifer, and Subrahmanyam 1998), i.e. a tendency to attribute past successes to one's own acumen, and past failures to vagaries of the market. Graham and Harvey (2003) analyze forecasts of CFOs (solicited in their surveys) regarding levels and volatility of short- and long-term excess returns. They find evidence of extrapolation from recent returns in one-year forecasts but nearly time-invariant long-term expectations. They also find a positive correlation between ex ante expected returns and ex ante volatility in the long-horizon forecasts.

Dominitz and Manski (2005) also examine household investor stock market beliefs using Michigan Survey data, though their data are drawn from different questions. In particular, they examine responses to a question regarding the probability that a typical diversified stock mutual fund will increase in value over the coming year. They document a substantial degree of cross- 
sectional heterogeneity in beliefs and find them to be systematically related to demographic characteristics such as gender and education. In addition, by exploiting the rotating panel design of the survey, they find these (heterogeneous) beliefs to exhibit "considerable temporal stability." Finally, they find the time-series pattern of monthly mean responses to be consistent with the hypothesis that the average investor believes that stock market performance is persistent from one year to the next.

Like these recent studies, we also examine whether investors extrapolate future returns from past experience. Different from most survey analysis, though, our data allow us to investigate how investors' beliefs regarding the stock market - such as expected returns and perceived market risk - respond to their perceptions about economic conditions. ${ }^{2}$ While the time-series dimension of our data only spans four years, we exploit substantial cross-sectional variation in perceptions about current and future business conditions to help identify the link between expectations of stock market returns and macroeconomic performance. Moreover, we are able to validate the relevance of investor's stock market expectations by relating them to selfreported portfolio allocations.

In short, our findings suggest that expected returns over medium-term and long-term horizons are extrapolated from past realized returns. They also indicate that a more optimistic assessment of expected macroeconomic conditions coincides with higher expected returns and lower expected volatility. This would imply that, at least for household investors, forwardlooking Sharpe ratios are higher when the economy is expected to be strong. Results are given added credence by the empirical finding that reported portfolio concentrations in equities tend to be higher for respondents who anticipate higher returns and lower uncertainty. Overall, the findings lend support to the hypothesis that equity valuations are lower during recessions - and subsequent returns are higher - because of undue pessimism about future returns, rather than high risk aversion.

\footnotetext{
${ }^{2}$ In a broader analysis of measures of consumer confidence, Dominitz and Manski $(2003,2004)$ document a positive correlation between expected business conditions and the perceived probability of a positive return.
} 
The rest of our study is structured as follows. Section 2 describes the survey instrument and discusses data construction and quality. Sections 3 and 4 focus on time-series and crosssectional determinants of investor expectations of stock market returns, respectively. Section 5 takes up investors' assessments of stock market risk. The penultimate section analyzes the relationship between investor actions and their reported beliefs, and then imputes investorspecific values of relative risk aversion and evaluates the resulting distribution of preference parameters. Section 7 concludes.

\section{Data and Variable Construction}

\section{A. Survey description}

Our data are obtained from a special section of questions about equity investments that Federal Reserve staff drew up for the Michigan Survey of Consumer Attitudes conducted by the Survey Research Center (SRC) at the University of Michigan. Each month, the SRC conducts a minimum of 500 phone interviews, which are used for the computation of a number of commonly cited gauges of the macroeconomy, such as the Index of Consumer Sentiment. Special questions on stock market perceptions, described in greater detail below, were asked over the period from September, 2000 through October, 2004 (albeit at uneven intervals) of the subset of respondents with stock holdings in excess of $\$ 5,000$. Between 35 percent and 45 percent of respondents satisfied the stock holdings criterion, consistent with the 40 percent share of such households in the U.S. population documented by the 2001 Survey of Consumer Finances. These household investors form the basis for our study.

The first two pages of Appendix A contain a list of questions asked on the special section of the Survey of Consumer Attitudes. ${ }^{3}$ We parse these questions into 3 groups: those asking about expected stock market returns over various horizons, those asking about the likelihood of

\footnotetext{
${ }^{3}$ The composition of questions in this section varied somewhat from survey to survey. In particular, some of the questions (e.g. the probability of average long-term stock returns being less than 5 percent per year) were kept off the three most recent surveys. The use of these questions will be described later in text.
} 
specific realizations of stock market returns, and those asking about respondents' current portfolio choices and portfolio changes in response to a hypothetical adjustment in distribution of expected returns.

Appendix A also contains a subset of the questions that make up the monthly Survey of Consumer Attitudes. The Survey asks a broad array of questions on respondents' expectations about economic conditions, both present and future, and on their assessment of their own economic circumstances and prospects. In addition, the Survey collects basic demographic information on respondent's age, education, income, and family status.

\section{B. Survey data quality: Do respondents have a clue?}

A widely understood weakness of survey data is that survey respondents might not take questions seriously, might make up answers to please the interviewer, and may be too illinformed on the subject of the survey at hand. Yet, survey data have been steadily gaining influence in the economics literature and a number of leading surveys (Survey of Consumer Finances, Panel Study of Income Dynamics, and Health and Retirement Survey, among others) have become commonplace in empirical research on consumer behavior. Indeed, it is difficult to imagine an alternative source for information on individual investors' expectations of market conditions. Still, in deference to the possible quality problems, we have taken some steps to examine response quality and to minimize potential noise in our data.

We begin by gauging the extent of survey respondents' general knowledge about the stock market by examining answers to the following question: "thinking about a diversified portfolio of stocks, what would you guess was the average annual return earned over the past 10 years?"4 Statistics summarizing the respondents' perceptions of past stock market performance are juxtaposed with actual realized returns in Figure 1.

The dots in Figure 1 plot the mean perception of past returns by survey month, while the bars depict the interquartile $\left(25^{\text {th }}\right.$ to $75^{\text {th }}$ percentile) range. The actual realized returns, defined as

\footnotetext{
${ }^{4}$ This question was asked on surveys spanning the period from September 2000 through January 2003 and also on the October 2004 survey.
} 
the geometric average return over the previous 120 months, are plotted by the hollow circles. Note that while surveys were not conducted at regular intervals, the results are plotted in calendar time. The series of actual past 10 -year average returns is surprisingly variable in our sample, starting at a high of 19.4 percent in September 2000 and reaching its lowest value of 9.0 percent by January 2003. The mean and the interquartile range of respondents' recalled market return also declined through the end of 2001, although the range of movement was much more limited. In particular, most respondents substantially underestimated the past 10 -year return in the early surveys, perhaps reflecting a tendency to provide answers weighted toward perceptions of longer-run experience.

To get some sense of the quality of survey responses, i.e. whether recalled past returns provide some indication of knowledge - we briefly examine whether the pattern of recall errors is systematically related to respondent characteristics. In particular, we calculate the absolute value of the recall error - the difference between recalled and actual 10-year market returns and regress this gauge of knowledge on demographic and stock ownership characteristics. In addition, we include two binary measures of response quality constructed from the survey interviewers' coded assessments of a respondent's "level of understanding" ("excellent" or "good" vs. "fair" or "poor") and "attitude" ("friendly and interested" or "cooperative" vs. "impatient" or "hostile"). The results, shown in Table 1, generally suggest that the accuracy of a respondent's recall of past returns improves with both wealth and education, as well as other indicators of financial market knowledge.

The first regression is run over the entire sample; in all cases, time dummies are included but not shown in the table. In particular, the recall error tends to decline with an increase in either the respondent's education (peaking at college level) or the dollar value of their stock holdings. For instance, the marginal effect of having a college degree, relative to no college education, is a 0.86 percentage point reduction in error. For households with more than $\$ 200,000$ in stocks, the average error is about 1.5 percentage points smaller than those with less than $\$ 25,000$ in stock. Another reassuring pattern is that errors tend to be smaller (about $3 / 4$ of 
percentage point) for those respondents who report being the primary investment decision-maker of the household. Controlling for age, years of investment experience did not matter. Finally, respondents whom the questioner reported as having an excellent or good (overall) understanding of the survey questions had smaller recall errors.

Because the errors in the first few surveys were much greater in magnitude (with a significant downward bias), we re-estimate this regression with the year 2000 observations excluded. In general, the results in this subsample (shown in the second column) are similar, suggesting that the relationship between error size and households characteristics is robust to sample period. Finally, it is instructive to examine the roughly 13 percent of the respondents who were asked this question but declined to provide an answer. The third column shows the results of a probit which estimates the effects of respondent characteristics on their propensity to refuse to answer the question (coded in survey as "don't know"). Although some of the characteristics that predict larger recall errors (e.g. education and gender) are also associated with the greater likelihood of refusal, others, such as the effects of stock ownership and level of household understanding, are not.

With these results in mind, we define a "data quality filter" that eliminates observations having an a priori low quality assessment. First, we exclude respondents that failed to provide an answer to one of the three main questions about anticipated stock market returns. This filter reduces our sample from 3,387 to 2,812 observations, about 17 percent. Second, we exclude observations where the respondents were rated by the interviewer to be in the bottom two categories of either "understanding" or "attitude". In addition, for reasons discussed in more detail in section 5, we excluded respondents that gave 50/50 answers to all three questions soliciting probabilistic responses to hypothetical situations. These two filters together eliminated 163 observations, or $5.8 \%$ of the sample with complete responses to the special survey section.

\section{The Time Series of Expected Returns: Evidence of Extrapolation}


Our analysis of the survey responses begins by focusing on the time series dimension of respondents' expected returns, which also facilitates some simple comparisons of our data with that from other surveys. Here, we focus on one of the central questions of this paper: to what extent are household investors' expectations of future stock market returns influenced by their recent historical experience?

\section{A. The basic pattern of responses}

Figure 2A plots responses, by survey month, from September 2000 through October 2004, to the two questions asking about average annual returns expected on a broad market portfolio. The solid circles depict the mean response to the following question: "what annual percentage rate of return would you expect a broadly diversified portfolio of U.S. stocks to earn, on average, over the next ten to twenty years?" The vertical lines show the interquartile range of those responses. The mean response for expected 10-20 year returns is highest in the first two surveys, gradually slides lower during the next two years, and then rebounds in more recent surveys. This pattern is even more apparent in the mean annual return respondents expected over the next 2 to 3 years (shown by squares), which starts close to the same level and bottoms out below 8 percent in July of 2002. Similar to the findings in Harvey and Graham (2003), expected returns over the shorter horizon are more volatile than those expected over the longer horizon.

Juxtaposed against this representation of expected returns, the hollow circles show the realized geometric average annual return over the previous 10 years (120 months). Expected future returns over both horizons (both means and interquartile ranges) appear to be highly correlated with the realized past 10-year return on the S\&P500. Indeed, the correlation between the mean of expected returns and the actual past returns is 0.896 and 0.717 for the medium- and long-term horizons, respectively.

Although this inference is drawn from a short time series, the coherence between past and expected returns is quite strong. As shown in the next section, this relationship is not very sensitive to the particular measure of past returns, as long as past returns span at least a few 
years. To examine whether the time series pattern of expectations would look much different on a "wealth-weighted" basis, we divide the sample into two groups according to whether the respondent's reported stock market wealth is above or below $\$ 75,000$ (roughly the midpoint of reported stock holdings). Figure 2B displays expected 3-year returns for the two subgroups. Overall, there appears to be little difference in the evolution of expectations for the two subgroups, though the dispersion of expectations among respondents with large stockholdings tends to be somewhat tighter. ${ }^{5}$

We further subdivide the subsample with large stockholdings into two subsets: those where respondents reported having the primary responsibility in the household for investment decisions versus those reporting otherwise ("spouse", "share with spouse", or "someone else"). The time series pattern of average expectations for these two groups (shown in Figure $2 \mathrm{C}$ ) is again largely indistinguishable. Thus, we are left with results suggesting that most household investors, regardless of wealth, have expectations that look extrapolative. As we will show below, these expectations would look quite different from conditional expectations inferred from models using ex post realized returns.

\section{B. Regression-based evidence of extrapolation}

In order to quantify the apparent extrapolation, and to test its robustness, we run a series of regressions with the respondent's expected annual return as the dependent variable. In each case, a measure of expected returns is regressed on some measure of past actual returns using the robust regression procedure in Stata. This procedure uses iterative GLS regression (Hamilton's (1991) robust regression) that applies progressively smaller weights to outliers.

Results for the 2-3 year expectation are shown in panel A of Table 2, while those for the 10-20 year horizon appear in panel B. The first column shows the results from simply regressing expected return on the past return on the S\&P 500 over the previous 36 months. The coefficient

\footnotetext{
${ }^{5}$ This finding is consistent with the result in Vissing-Jorgensen (2003), which suggested that expected returns from the UBS/Gallup poll was positively correlated with the level of the stock market for both high-wealth and lowwealth households.
} 
estimate, 0.108 , implies that a 10 percentage point swing in past returns (such as that observed over our sample period) raises expected return by about 1 percentage point, a fairly modest though statistically significant effect. Panel B shows the analogous regression with the 10-year expected (annual) return as the dependent variable. Here the estimated coefficient, at 0.046 , is smaller but still significant. Collapsing the data into survey-level means produces 20 observations of mean investor expectations. Estimating simple macro regressions on this sample also produces positive and statistically significant coefficients on past returns for both horizons.

The second regression in each panel examines robustness to the precise measure of past return employed. The independent variable here is instead an approximate 3-year return, where the starting point is smoothed by using a 12-month centered average value (6 months forward and backward) of the S\&P500 total return index 36 months earlier. ${ }^{6}$ The resulting coefficient estimate is a bit larger in this case while there is little change in the t-statistics.

In the third specification, we add two explanatory variables: (i) the past 3-month return, and (ii) a control for idiosyncratic perceptions, the respondent's recall error - defined as the difference between recalled and actual past 10-year return. As can be seen, the past 3-month return has no incremental explanatory power for expected returns, at either horizon. This suggests that investors do not tend to extrapolate from very recent performance in predicting medium- to long-run returns.

Arguably, in light of the results in Table 1, including the recall error allows us to control for the quality of investor knowledge. Since the recall error is defined in relative terms, its value is higher for respondents with high estimates of past returns. However, even if households do not extrapolate from past performance, we would expect a higher recall error to be associated with a higher prediction for expected return in the future. In any case, the coefficient on the recall error is 0.28 in panel A and 0.33 in panel B. Since the addition of the respondent-specific

\footnotetext{
${ }^{6}$ Algebraically, the approximate 10-year return is defined as $\left[\mathrm{SP}_{t}-(1 / 12) *\left(\mathrm{SP}_{t-42}+\mathrm{SP}_{t-41}+\ldots+\mathrm{SP}_{t-3 l}\right)\right]^{1 / 3}$, where $t$ is the date of the survey.
} 
recall error introduces a source of cross-sectional variation, the resulting R-squared values rise substantially. Perhaps more surprising, including this measure of individual perceptions does not eliminate the apparent effect of actual past returns on expected returns. The coefficient on actual past returns is larger and highly significant for both expectation horizons. Holding the recall error constant, the estimated time-series effect of actual past returns rises to about 0.2 for the 3 year expected return (panel A) and 0.13 for the 3-year expected return (panel B). ${ }^{7}$

The fourth specification is similar to the previous one, but uses a different horizon for the past return - the geometric average return over the previous ten years (120 months). The coefficient estimate on the past ten-year S\&P 500 return is substantially larger in magnitude, reflecting its smaller variance. It is also highly significant, and the R-squared is even a bit larger than in the previous specification, confirming once again the extrapolative link between both individual and time-series measured of past returns and stock market expectations. Finally, changing the measure of past return has little effect on the other coefficient estimates.

\section{A Caveat: The Importance of Framing in Surveys}

There remains an important consideration regarding exactly how one should interpret answers to questions about expected returns. As Shiller (2003) notes, many people answer such survey questions without entirely understanding the concept. We are able to examine this issue because, over much of the period covered by our survey, the Michigan Survey also included the following set of questions soliciting stock market opinions: (i) Do you expect stock prices to be higher, lower, or about the same 12 months from now? (ii) By how much (if not the same)?

We can thus estimate the respondent's "expectation" of stock market appreciation by combining the anticipated direction with predicted magnitude. The solid bars in Figure 3 depict the mean of the respondents' predicted twelve-month stock price change by survey. The hollow bars plot the mean expected annual return over the next 2-3 years. Clearly, these measures

\footnotetext{
${ }^{7}$ The total derivative of expected returns with respect to actual past returns is equal to the difference between the estimated coefficients on past returns and the recall error. In both panels, this effect is positive $(0.095$ and 0.36 , respectively) and strongly significant.
} 
capture different concepts. Since the dividend yield on any broad market index was below two percentage points over this entire period, the substantial discrepancy between the two series cannot be accounted for by the dividend component of returns. Moreover, the monthly survey means of the two questions exhibit very little correlation.

While it is possible that the disparity is attributable to the difference in horizons, a comparison of these answers to those from the UBS/Gallup survey of individual investors indicates otherwise. The UBS survey asks for respondent's "expected return" over the next 12 months, and the dotted line in Figure 3 plots the monthly mean response to this question over the period covered by our survey. As can be seen, the answers to the UBS survey are much closer to the expected annual return over 2 to 3 years than to the expected 12-month price change.

In fact, contrasting the answers to these differently framed questions leads to a paradox. While none of the Michigan survey respondents reports a negative "expected return" over either 2-3 year or 10-20 year horizon, between 10 to 20 percent of respondents in each survey month predict that stock prices will go down over the next 12 months. A plausible interpretation of this contrast is that survey respondents' answers about expected returns are strongly influenced by their views on long-run expected returns, irrespective of the horizon they are asked to consider. It is likely that many non-expert respondents are exposed to the expected return concept only in the context of long-term predictions. If so, their answers may be "anchored" to perceptions about long-term returns. In contrast, when asked about the anticipated level of stock prices in 12 months, responses are more likely to be anchored at the current level of stock prices, suggesting some degree of agnosticism about the short run.

To evaluate this hypothesis, we added a question on expected 12-month stock market returns in the October 2004 survey. The cross-sectional correlation between expected 12-month returns and expected 2-3 year returns was 0.7. By contrast, correlation between expected 12month price changes and expected 2-3 year returns did not exceed 0.3 in any of the 16 Michigan surveys where both questions were asked, and was statistically indistinguishable from zero in 3 of those surveys. 
With this discussion in mind, we are inclined to interpret responses to questions about expected returns as reflecting a longer horizon than that stipulated in the question. For instance, it seems reasonable to think of the 10-20 year return expectation as being a "long run" expectation for many respondents, which might not be influenced by expected near-term economic conditions.

\section{Determinants of expected stock market returns}

As discussed earlier, there is a vast and growing empirical and, more recently, theoretical literature aimed at exploring the pattern of time variation in expected stock returns. The common interpretation of most findings is that expected returns vary with the business cycle. In particular, expected returns are thought to be lower when times are good and higher when the economy is in recession, that is, the risk premium is thought to be countercyclical. This is frequently rationalized by the perception that risk tends to be higher when economic conditions are less favorable. Alternatively (or in addition), aversion to financial risk could be higher when incomes are lower. Campbell and Cochrane (1999) formally model time-varying risk aversion driven by habit persistence in consumption patterns.

We evaluate the relationship between the perceptions of the business cycle and expected returns by relying on direct survey responses. The Michigan survey questions include several inquiries regarding the respondent's perception of business and financial conditions, as well as

their own economic prospects, over horizons varying from one to five years. The question from which we draw our primary measure of perceived economic conditions is the following:

"Looking ahead [is it more likely that the U.S. will have] continuous good times during the next 5 years or so, or that we will have periods of widespread unemployment or depression, or what?"

The answers are placed into five categories by the survey-giver: (i) bad times, (ii) bad times, qualified (not good), (iii) pro-con, (iv) good times, qualified (not bad), or (v) good times. We concentrate on this question because it focuses on economic activity, whereas alternative 
questions in the survey refer to anticipated business and "financial" conditions. For most of our regression analysis, we represent the responses to this question with a numerical variable, Good Times-5yrs, which takes values running from -2 (bad) to 2 (good).

We primarily interpret this variable as a measure of what the household investor believes about economic prospects, that is, their view of the market consensus. Under this assumption, the conventional interpretation of the dynamics of conditional stock returns would predict that expected returns are negatively related to Good Times-5yrs. On the other hand, one could argue that this variable may also be correlated with expected news, that is, news the respondent expects to be revealed to the market in the future. We address this alternative interpretation below.

A second measure of expectations used in our analysis is drawn from the following question:

And how about a year from now, "do you expect that ... business conditions will be better or worse than they are at present, or just about the same"

The responses are simply coded: worse, better, or the same. We again quantify them with a single variable, Better Conditions-1yr, with a value of -2 (worse), 0 (same), or 2 (better). Unlike the first sentiment measure, this measure does not gauge the expected level of macroeconomic well-being but, rather, the expected change in well-being (and over a shorter horizon). It seems somewhat more plausible to interpret this variable as an indicator of economic news the respondent anticipates. To the extent that respondents perceive disagreement on the direction of the economic news over the coming year, their expected return on stocks - at least their short-run expected return - could be positively related to their response to this question.

The dependent variable in the regressions in Table 3 is the reply of respondent $i$ surveyed at time $t$ about her assessment of expected, or likely, returns over the medium- or long-term horizon $h$ gauged by the survey. The empirical analysis of expected returns follows a common structure given by:

$$
R_{i, t}^{\mathrm{e}, \mathrm{h}}=\beta_{1} r_{\mathrm{t}-120}+\beta_{2} \mathrm{E}_{\mathrm{i}}\left[\text { macro }_{\mathrm{t}, \mathrm{t}+60}\right]+\beta_{3} \mathrm{E}_{\mathrm{i}}\left[\Delta \text { macro }_{\mathrm{t}+12}\right]+\beta_{4} D_{\mathrm{i}, \mathrm{t}}+\varepsilon_{\mathrm{i}, \mathrm{t}}
$$


The explanatory variables are broken into several groups: actual realized market returns over the previous 10 years $\left(r_{\mathrm{t}-120}\right)$; the self-reported outlook on general business conditions over the next 5 years $\left(\right.$ macro $\left._{\mathrm{t}, \mathrm{t}+60}\right)$; self-reported expected change in economic conditions over the next twelve months $\left(\Delta\right.$ macro $\left._{\mathrm{t}+12}\right)$; and a collection of demographic controls $\left(D_{\mathrm{i}, \mathrm{t}}\right)$ that include age, education, gender, and years of investment experience.

The estimation results for expected returns over the 10-year horizon are presented in columns (1) and (2) of Table 3. Parallel results for the 3-year horizon are shown in columns (3) and (4). The first specification in each pair excludes the past 10-yr return, the variable used earlier to measure the degree of extrapolation. In order to minimize the influence of outlier responses, we again use robust regression estimation throughout this section. ${ }^{8}$

Both measures of expected economic conditions have strong positive effects on expected returns. The positive coefficient on Good Times-5yrs suggests that conditional expected returns are procyclical, that is, these investors' expected returns appear to be higher when the economy is expected to be good. ${ }^{9}$ This finding illustrates a potentially fundamental difference between inferences based on ex ante expected returns and those based on ex post realized returns.

Still, one could conceivably argue that our measure of macroeconomic conditions (Good Times-5 yrs) does not necessarily serve as a pure state variable, but that it also stands in as an indicator of the respondent's idiosyncratic information, i.e. their opinion. In other words, similar to our interpretation of Better Conditions-1yr, this variable might also act as a proxy for news the respondent believes the market will learn over time. If so, it would be correlated with the respondent's anticipation of unexpected returns, that is, returns unexpected by the market but not

\footnotetext{
${ }^{8}$ Other alternatives included estimating a quantile (median) regression and truncation of the top and bottom percentile responses in each survey with subsequent OLS estimation. Both of these alternative methods produce results that are qualitatively similar to the robust regression and are available upon request.

${ }^{9}$ The regressions in Table 3 get much (but not all) identification from cross-sectional variation in beliefs about future business conditions and disagreement on where the economy is now. Hence, "procyclical" should be taken to mean not just the typical "as the business cycle evolves", but also "as the business cycle is perceived by respondents".
} 
the respondent. This would constitute a very different interpretation of the positive coefficient on Good Times-5 yrs.

To confront this competing interpretation, we attempt to separate the idiosyncratic (news) and the consensus components of this variable by subtracting the time-specific mean value of Good Times-5yrs from each respondent's answer. This produces a measure of the pure idiosyncratic component of expected economic conditions, equal to the deviation of the respondent's view from the (time $t$ ) average view. What is more, the time-series mean component can be interpreted as a measure of the consensus perception of economic conditions. Under the conventional view that expected returns are countercyclical, this component clearly ought to have a negative coefficient.

Table 4 shows regressions analogous to those in Table 3, but with Good Times-5yrs decomposed into Good Times-5yrs Deviation and Good Times-5yrs Mean. As shown, in each specification the effect of the idiosyncratic component of expected macro conditions is positive and significant. On the other hand, the coefficient estimate on the consensus component is sensitive to the inclusion of past 10-yr return. When past return is excluded, Good Times-5yrs Mean has a large and statistically significant coefficient, indeed, much larger than the coefficient on the idiosyncratic component. When past return is included as a regressor, the coefficient on Good Times-5yrs Mean becomes insignificant (and changes sign), while the past return variable has a significant positive effect.

These results suggest the following interpretations: either household investors extrapolate from recent years' stock returns in forming their expectations of the macroeconomy or their expected returns are procyclical. Either way, the results contradict the standard view on the cyclicality of expected returns and indicate the presence of pervasive non-rational beliefs. Indeed, it may be that both interpretations are correct. In particular, investors may associate a "good" stock market with good economic times, and they may also tend to expect unusually good times (or unusually bad times) to persist longer than normal. 
These conclusions are not sensitive to our choice of demographic controls, most of which have little explanatory power. In fact, only gender has a sizable effect on medium-term expectations, with male respondents expecting 80 to 100 basis points higher return, and this effect dissipates in the longer-horizon regressions. Perhaps more surprising is the lack of any effect of investor experience and age, contrasting with the Vissing-Jorgensen (2003) finding that more experienced and older investors in the Gallup/UBS polls were consistently less optimistic about expected returns over the 1998-2002 period. When we allow for time-varying experience (and age) effects, we still fail to detect a moderating influence of experience on market expectations in our earlier surveys.

Finally, before turning to an analysis of risk perceptions, it is interesting to contrast our survey-based measure of expected returns (and one from the UBS/Gallup survey) to the estimates of conditional expected returns generated from the traditional approach -- regressing realized returns on predictive variables. To illustrate the contrast, we focus on the log consumption-wealth ratio $(C A Y)$, the conditioning variable that Lettau and Ludvigson (2001, 2004), found to best predict stock returns. In particular, they find that the coefficient on $C A Y$ in excess return and real return regressions to be positive and significant, and more robust to sample period than the dividend-price ratio; thus, $C A Y$ is presumed to vary directly with expected stock returns.

In Figure 4, the round (blue) dots represent the mean values of expected 3-year annual return from the Michigan survey. The connected (red) squares represent the mean values for the expected 12-month return from the UBS/Gallup survey. The (green) line is a plot of the deviation of $C A Y$ from its mean value. ( $C A Y$ was converted to a monthly series by using linear interpolation between end-of-quarter values.) What is obvious from the chart is that surveybased measures of one- and three-year expected returns are strongly negatively correlated with $C A Y$, at least over the sample period at hand. This would suggest that CAY is an extremely poor measure of investor expectations of market returns, at least for household investors (including those holding more than $\$ 75,000$ in stocks). Thus, to argue that conditional expected returns 
based on $C A Y$ (or the dividend-price ratio for that matter) are representative of the "market" expectation, one must believe that non-mutual fund institutional investors not only have the opposite beliefs of even wealthy households, but that those institutions are also much more important for asset price determination.

\section{How uncertain are stock market returns?}

A more complete understanding of household investor beliefs on prospective stock market returns requires analysis of their perceptions about risk. We draw our main inferences in this regard from the survey question that asks the respondents to assess the likelihood of a particular stock market outcome. Specifically, the question reads "what do you think the chance is that the average return over the next 10 to 20 years will be within two percentage points of your guess, that is between $R^{e}-2$ and $R^{e}+2$ percent per year ?" Taken literally, the response to this question can be interpreted as an estimate of the probability mass illustrated by region $\mathrm{A}$ in the top panel of Figure 5.

The distribution of raw responses to this question, together with some summary statistics, appears in the two lower panels of Figure 5. The empirical distribution spans the entire range of allowable responses, with about five percent of investors reporting extreme beliefs, that is, either a 0 or 100 percent chance. Another notable aspect of the distribution is the large relative density of responses at 50 percent, which is a common feature of survey questions that elicit probabilistic assessments (see Bruin, et. al. 2002 and references therein). As argued by Bruin, et al. (2002), a 50/50 response to probabilistic survey questions not only reflects a numeric opinion, but also can indicate epistemic uncertainty - a self-perceived lack of knowledge. ${ }^{10}$ Consequently, the frequency distribution in Figure 5 likely puts too much weight on 50 percent relative to a counterfactual in which every respondent has a concrete point of view regarding the likelihood of

\footnotetext{
${ }^{10}$ A similar argument is put forth in Tversky and Kahneman (1974), who attribute the prevalence of 50/50 responses to the behavioral bias called 'anchoring'. In their view, respondents often answer questions by starting from an initial value, or anchor, and adjusting insufficiently from that value to arrive at a response. Tversky and Kahneman found that, when experimental participants are asked open-ended questions like: "What is the probability that $x$ will occur?" they tend to anchor on $50 \%$, which could be interpreted as expressing "no opinion".
} 
specific stock market returns. We do not explicitly correct for this bias but, as mentioned earlier, we did exclude those observations in which the respondent always gave " 50 percent" answers to questions soliciting probabilistic responses to hypothetical situations. ${ }^{11}$ It is also worth noting that the frequency distribution of uncertainty about expected returns for households without college degree (white bars) is skewed to the left relative to college-educated households (dark bars). In other words, college-educated households exhibit greater confidence in their assessments of future returns, just as they showed a more precise recall of past stock returns in Table 5.

We can calibrate the perceived risk of equity returns implied by the survey responses in terms of a more conventional metric by backing out an estimate of the standard deviation each respondent associates with average market returns, conditional on some distributional assumptions. For the purposes of this exercise, we assume that annual stock market returns are lognormally distributed. In turn, since the lognormal distribution has finite second moments, time averages of annual market returns would be asymptotically normal. Thus, we can back out standard deviations by applying the inverse of standard normal cdf to a properly scaled measure of the responses. Denoting reported $\operatorname{Prob}\left(R^{\mathrm{e}}-0.02<R<R^{\mathrm{e}}+0.02\right) \equiv$ Within2, we calculate:

$$
\sigma_{10-20}=-2 / \Phi^{-1}(0.5(1-\text { Within } 2)) \text {, where } \Phi^{-1}(\cdot) \text { is the inverse of standard normal cdf. }{ }^{12}
$$

The lower panel of Figure 5 reports the distribution of imputed values of the standard deviation of average returns over a 10 to 20 year period $\left(\sigma_{10-20}\right)$. The midpoint and the interquartile range of these imputed standard deviations are somewhat lower than historical experience, though not unfathomable. For instance, assuming a 20 -year horizon, the median implied standard deviation of 2.96 percent would translate to an annual volatility of 13.2 percent $(=2.96 * \sqrt{2} 2)$ percent, about two-thirds of the historical level of 18 percent (Campbell, Lo, and

\footnotetext{
${ }^{11}$ In addition to indicating the influence of epistemic uncertainty, giving a 50/50 response to all probabilistic questions probably likely signals a propensity to give lower-quality responses.

${ }^{12}$ Under this assumption, we cannot impute $\sigma_{10-20}$ for respondents that give values of 0 or 100 percent for Within2. However, such responses are very infrequent and neither of them appears to be a meaningful reply even in its raw form.
} 
MacKinlay, 1997). On the other hand, assuming a 10-year horizon leads yields an implied annual return volatility of only 9.4 percent. $^{13}$

Identifying factors that explain the variation in Within2 could serve to confirm its utility as a proxy for perceived risk and should be interesting in its own right. To begin with, we are interested in examining the link between perceived risk and expected business conditions. The research on time-varying volatility generally finds strong countercyclical conditional volatility in stock market returns (see, for example Engle (2003) and cites therein). Most recently, Brandt and Kang (2004) use a latent VAR approach to stock returns data from 1946-98 and conclude that "whenever the economy comes off the peak of a cycle, the conditional volatility rises immediately" (p. 220). One intuitive explanation for this relationship is that leverage rises in economic downturns, making equity claims on the firm riskier. Thus, we would expect to see an inverse relationship between investors' outlook for economic conditions and their assessment of stock market risk.

We also explore whether variables that measure a respondent's general knowledge or confidence also influence their perception of market risk. Earlier literature identified overconfidence, nurtured by biased self-attribution, as a mechanism that generated inflated selfassessments of forecasting ability and, thus, a less-than-realistic degree of perceived risk (Gervais and Odean, 2001; also see Hirshleifer, 2001 and references therein). To provide some controls for these effects, we include the probability the respondent places on receiving real income gains in the future, and a variable indicating whether their own house recently appreciated in value. In addition, we include indicators of education level as well as the gender of the respondent.

\footnotetext{
${ }^{13}$ Equation (2) suggests that respondents' probability assessments contain information on volatility of stock market returns. However, their replies may well conflate notions of uncertainty and risk, with respondents more confident in their knowledge of finance interpreting the question as a referendum on their forecasting ability and not on the underlying risk in the stock market. In this case, higher levels of Within2 would be indicative of overconfidence in the operational sense of Gervais and Odean (2001). The relative importance of these two notions in investor replies presents a difficult and interesting question, which is left for future research.
} 
Finally, we include a purely behavioral variable, which tests for the influence of the "representativeness" heuristic proposed by Tversky and Kahneman (1982). They argue that the likelihood someone assigns to an outcome can be excessively influenced by whether that outcome is "representative" of the available evidence. One measure of the "representativeness" of a respondent's expected future return would be its similarity to the recent historical returns observed by the respondent. Thus, we measure the "representativeness" of a respondent's expected 10-year average return $\left(R^{\mathrm{e}}\right)$ by the (absolute) discrepancy between $R^{\mathrm{e}}$ and the respondent's own recollection of average returns over the past 10 years. The representativeness hypothesis predicts that, if the respondent's $R^{\mathrm{e}}$ is close to their recollection of recent historical market returns, then they will be more prone to assign a high probability to realizing a return in the neighborhood (within 2 percent) of $R^{\mathrm{e}}$.

The first column of Table 5 shows the results from a regression of the raw probability assessment on the two measures of expected macroeconomic conditions from the previous section plus time controls. ${ }^{14}$ For ease of interpretation, we define the dependent variable, Uncertainty, as the complement of Within2 i.e., the probability that average annual returns fall outside the 2 percentage point band around the respondent's expected return. Thus, regressors with positive coefficients have a positive effect on perceived risk.

As hypothesized, the results of the first regression imply that stronger expected economic conditions are associated with less uncertainty. In conjunction with the results of the preceding section, this implies that respondents translate their expectations of business conditions into two distinct scenarios - expectations of economic expansion are linked with high returns and low volatility, while expectations of downturn are linked with both low returns and high volatility. In other words, investors with a more optimistic economic outlook anticipate the stock market to

\footnotetext{
${ }^{14}$ We use raw probability responses instead of imputed standard deviations on the left-hand side in order to minimize sample attrition stemming from purely mechanical imputation problems discussed earlier. This also allows the analysis to be robust to other possible return distributions, since the relationship between a covariate and a raw probability response will have the same sign as that between a covariate and an implied standard deviation for any underlying distribution.
} 
yield higher returns with lower risk. ${ }^{15}$ This "good-good" association is similar to that reported by Shefrin (2001), which finds that investors judge "better" stocks (for long-run investment purpose) as being both less risky and having a higher expected return. ${ }^{16}$

Augmenting this regressor set with variables that measure the respondents' knowledge of financial markets and their self-confidence (column (2)) only slightly weakens the estimated inverse relationship between uncertainty and expected (longer-term) business conditions, as reflected in Good Times-5 yrs. On the other hand, Better Conditions-1yr is now only marginally significant. Its weaker connection to uncertainty might reflect the shorter-term focus of this variable, which contrasts with the longer-term orientation of our uncertainty measure.

Looking down the table, we find that those having done well in financial matters recently (saw appreciation in their home value) and those expecting to do well in the future (expecting income to outpace inflation) report lower levels of Uncertainty. In addition, it appears that lower assessments of Uncertainty are provided by respondents who are the main household investment decisionmaker, and by those of male gender. This is consistent with evidence from psychology, summarized in Barber and Odean (2001), which supports the notion that men will be more "overconfident" than women in their ability to perform well on tasks related to finance, traditionally considered to be a more "masculine" pursuit (see esp. Beyer, 1990).

Demographic controls also help explain the variation in Uncertainty, with tests of joint significance of age and education dummies producing F-statistics with p-values of 0.04 and 0.001 respectively. Respondents that are older and/or have higher education levels report lower

\footnotetext{
${ }^{15}$ The estimated negative relationship between macroeconomic expectations and the level of ex ante volatility is independent of the presence of expected returns as an explanatory variable. It is also preserved when the dependent variable is transformed to an imputed standard deviation (or a log thereof).

${ }^{16}$ As Shefrin (2001) notes, such a finding is consistent with the idea of judging on "representativeness." If a person believes that the market, or an individual stock, is "good" by some measure and if she makes judgments by "representativeness," she will judge its risk and expected return to be such that each is most "representative" of its being "good." If, as can reasonably be assumed, low risk and high returns are each associated with a "good" market or "good" stock, judging by "representativeness" will likely lead a person who believes the market or a stock to be "good" to judge its risk to be low and expected return to be high.
} 
levels of uncertainty. Moreover, when we control for age and education, years of investment experience have only a marginally significant ( $\mathrm{p}$-value of 0.1 ) negative effect on expected risk.

Finally, as shown in column (3), Uncertainty is positively related to the discrepancy between expected future returns and recalled past returns. In other words, less consistency between expectations and evidence coincides with greater uncertainty about future stock returns, yielding evidence in support of the representativeness heuristic. Indeed, this coefficient implies a fairly sizable effect: boosting the discrepancy 10 percentage points is estimated to boost uncertainty - the probability of not coming within 2 percent of expectation - by 6.9 percentage points. Although many observations are excluded from this regression (due to fewer surveys containing data on recalled past return), the other variables have similar effects to those found in the second specification.

\section{Investor actions and expectations}

In this section, we examine the determinants of self-reported equity portfolio exposures of survey respondents. Obviously, the relevance of our findings regarding household investors' perceptions of risk and return hinges on whether those perceptions, as we measure them, actually correlate with their portfolio allocation decisions. This section provides some evidence in this regard, using information on respondents' share of financial wealth residing in stocks or stock mutual funds (question AA5b in Appendix A, added to the surveys in June 2001). In particular, the respondents were asked to choose one of five portfolio possibilities: (i) less than 10 percent invested in equities, (ii) from 10 to 25 percent, (iii) from 25 to 50 percent, (iv) from 50 to 75 percent, or (v) over 75 percent. Responses were fairly evenly distributed, with the largest group of investors (26 percent) claiming that 10 to 25 percent of their financial assets were in equities, and 12 percent of investors claiming their equity shares were in excess of 75 percent. ${ }^{17}$

\footnotetext{
${ }^{17}$ This distribution is markedly different from that of equity owners in the latest available Survey of Consumer Finances (SCF). In the 2001 SCF over one-third of investors held more than 75 percent of their financial wealth in equities, and only 9 percent had equity shares between 10 and 25 percent.
} 


\section{A. Estimating Portfolio Choice Regressions}

The first set of exercises involve regressing the self-reported equity allocation fraction on the fundamentals from standard asset-pricing models - the respondent's expected return on stocks, their assessment of risk in future stock market returns, and a risk-free rate. Since our dependent variable is discrete and follows a well-defined ordinal ranking, the determinants of equity share are estimated using both an ordered logit specification and OLS. In the OLS regression, we set the value of the independent variable at the category midpoint (e.g., 5 percent for the lowest group). In all cases, we measure stock market volatility as Uncertainty (the complement of Within2, defined in the previous section) which, in contrast to the imputed standard deviation, is well-defined for all observations and does not have a highly skewed distribution.

The first two columns of Table 6 show the estimated coefficients from fitting an ordered logit and an OLS regression, respectively, to the reported portfolio allocations. The set of explanatory variables is limited to expected excess return, Uncertainty, and a set of time dummies. ${ }^{18}$ Expected excess return is defined here as the respondent's expected 10- to 20-year average return on their own stock portfolio less the yield on the 10-year Treasury bond at the time of survey.

The estimated coefficients in the ordered logit regression in column (1) are statistically significant and consistent with theory: the probability of holding a larger equity portfolio share is increasing with expected excess returns and decreasing with Uncertainty. ${ }^{19}$ Since the OLS estimator is also consistent and more readily interpretable, our discussion focuses on the leastsquares regression results. As in the logit specification, OLS coefficient estimates in column (2) are statistically significant and consistent with theory. In particular, they imply that an increase

\footnotetext{
${ }^{18}$ With expected returns on the right hand side, robust regression methods are not as effective a control for the effect of outlier values of $R^{\mathrm{e}}$. Hence, we choose to remove investors that report average annual expected returns in excess of 25 percent over a long (10-20 year) horizon. Such investors amount to less than 3 percent of all respondents.

${ }^{19}$ When estimated at the median, probabilities of being in the top three equity share groups $($ fraction $>1 / 4)$ increase with $R^{\mathrm{e}}$ and decrease with expected volatility.
} 
in expected excess returns from, say 1.5 percent to 6 percent $\left(25^{\text {th }}\right.$ to $75^{\text {th }}$ percentile values), is associated with a roughly 4 percentage point increase in the portfolio equity share. A decrease in the Uncertainty of average returns, from 50 to 25 percent (also $25^{\text {th }}$ to $75^{\text {th }}$ percentile values), also results in an increase in equity share of about 4 percentage points.

Adding a number of demographic controls, column (3), does little to change the estimated OLS coefficients on expected excess returns and volatility. We find that, within our sample of household investors, older households do not have consistently lower portfolio equity shares, similar to the findings in Ameriks and Zeldes (2001). In contrast, both education and length of investment experience have strong positive effects on equity share. The latter finding likely reflects investor gains from participating in the bull market of the 1990's coupled with limited portfolio rebalancing.

Although these results are quite suggestive, it is difficult to judge the magnitudes of the estimated coefficients absent some normative benchmark. The classic portfolio choice models of Merton (1969) and Samuelson (1969) provide such a benchmark. These models assume that (i) investor preferences are described by a power utility function, (ii) returns are serially uncorrelated, and (iii) the investment opportunity set is static. Under these conditions, the portfolio share invested in stocks should be directly proportional to the expected risk premium and inversely proportional to the product of expected market variance and the coefficient of relative risk aversion. Algebraically, the optimal portfolio share of respondent $i$ is given by:

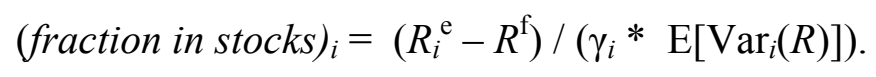

Taking logs on both sides of this equation leads to the following econometric specification:

$$
\log \left(\text { fraction }_{i}\right)=-\log \gamma_{i}+\beta_{1} \log \left(R_{i}^{\mathrm{e}}-R^{\mathrm{f}}\right)+\beta_{2} \log \left(\mathrm{E}\left[\operatorname{Var}_{i}(R)\right]\right)+\varepsilon_{i}
$$

The model predicts that $\beta_{1}=-\beta_{2}=1$. The advantage of this specification is that it provides a structural interpretation of the coefficients. However, it also requires us to drop observations for which expected excess returns are not strictly positive, as well as those for which the implied standard deviation of future returns is undefined. 
Table 7 shows the results of estimating (4) on a pooled cross-section of respondents using a set of survey dummies as time controls. The estimated elasticity of equity shares with respect to expected excess returns is positive and statistically significant. In addition, the elasticity with respect to expected volatility (measured as the square of the imputed standard deviation) is negative and significant. Although the two coefficients are of similar magnitude and have the predicted signs, they are much smaller than the theoretical value of unity. Of course, our measurements of investor expectations, particularly volatility, are probably quite noisy; thus, it seems likely that attenuation bias from the resulting measurement error pushes both $\beta$ 's towards zero. $^{20}$ In addition, though, it is quite possible that the sensitivity of portfolio choice to variation in expected excess returns or volatility is muted by transaction costs or inertia, which inhibits portfolio rebalancing.

Column (2) shows the results from estimating a slight deviation from the model in (4). In particular, we use the log of expected return $\left(R^{\mathrm{e}}\right)$ rather than the log of expected excess return. This has the advantage of not eliminating observations in which expected return is less than or equal to the risk-free rate and it also produces fewer negative outliers in the return variable (due to excess return being quite close to zero in many cases). Indeed, the coefficient on $R^{\mathrm{e}}$ in this regression is substantially larger (0.25), though still only a fourth of its theoretical value.

Ideally, expected excess returns would be computed using individual assessments of the risk-free rate. Such a question was asked in earlier surveys, but those surveys were missing the question on portfolio choice. Only five of the surveys (July-November, 2001) contain investorspecific information on both a self-reported expected yield on a "low-risk" alternative investment and portfolio equity share. Nonetheless, we re-estimate the first specification using excess return constructed with the self-reported risk-free return, shown in column (3). Although doing so drastically cuts down the number of observations, the results appear to be robust to this change.

\footnotetext{
${ }^{20}$ A standard remedy for measurement error consists of estimating instrumental variable regressions, where the instruments are (ideally) uncorrelated with the measurement error of the original regressor. Preliminary results using an estimate of expected volatility from the prob $\left(R_{i}^{\mathrm{e}}<5\right)$ question (AA10 in Appendix A) and 3-year excess return to instrument for $\left(R_{i}^{\mathrm{e}}-R^{\mathrm{f}}\right)$ and $\mathrm{E}\left[\operatorname{Var}_{i}(R)\right]$ in $(4)$, respectively, suggest that this is indeed the case.
} 


\section{B. Imputation of coefficients of relative risk aversion}

While we have shown that portfolio allocations of survey respondents are related to their self-reported expectations of stock market returns and uncertainty, little of the variation in equity allocations is explained and the magnitude of the coefficients are much less than predicted by a tractable but simplistic static model of portfolio allocation. Still, with all the ingredients at our disposal, it seems incumbent upon us to entertain the exercise of backing out the implied investor-specific coefficients of relative risk aversion from the Merton-Samuelson portfolio allocation rule in (3). ${ }^{21}$ While we do not regard this imputation as a serious attempt to calibrate investor preferences, it is a useful device for summarizing the implications of our findings.

Table 8A summarizes the distribution of investor coefficients of relative risk aversion, $\gamma_{i}$, which are backed out from equation (3). ${ }^{22}$ As shown, the resulting distribution of $\gamma$ 's is quite wide, with a median value of 8.1 and the interquartile range of 1.9 to 22.6. Since some survey respondents gave estimates of expected stock returns below the risk-free rate (and (3) doesn't contain a hedging component), nine percent of the estimates are negative.

The more interesting aspect of this exercise, however, lies in correlating the individual risk aversion coefficients with variables of interest. Following the main thread of this paper, we examine the relationship between anticipated macroeconomic conditions and the imputed $\gamma$ 's.

${ }^{21}$ Employing theoretical relationships to obtain estimates of consumer (investor) preferences from data has a rich tradition in economic literature. While many earlier studies focused on the representative consumer and aggregate data (e.g. Hansen and Singleton, 1983), recent work has increasingly turned to micro data to obtain distributions of various preference parameters. For example, Dynan (2000) uses PSID panel data to test for the presence of habit persistence in household consumption patterns. Halek and Eisenhauer (2001) estimate coefficients of relative risk aversion using life insurance data. Graham and Harvey (1996) impute the same coefficients for a sample of investment newsletters in their investigation of whether newsletter recommendations can forecast market volume and volatility. Barsky, et.al. (1997) use responses of the HRS participants to hypothetical questions about gambles on lifetime income to obtain estimates of risk aversion, intertemporal elasticity of substitution, and time preference.

${ }^{22}$ Recall that our measure of imputed standard deviation pertains to mean annual returns over a long (10-20 year) horizon. This measure is annualized here, which does not affect any cross-sectional or time-series comparisons. The portfolio problem above ignores a number of hedging demand factors. Among these is demand for hedging intertemporal changes in the investment opportunity set (Merton, 1971; Campbell and Viceira, 1999) and labor income shocks (Viceira, 2001). Both of these factors would influence the imputation of relative risk aversion, although the direction and magnitude of these effects will vary with characteristics of individual labor income processes and the nature of expected changes in the distribution of returns. 
The results, summarized in Table $8 \mathrm{~B}$, are counterintuitive. Investors who either believe that business (or economic) conditions will be better a year from now, or will be good throughout the next five years, have substantially higher imputed values of $\gamma$ compared to the more pessimistic respondents. This finding contrasts sharply with the existing rational asset pricing models that have an explicit role for business cycles. For example, Campbell and Cochrane (1999) show that investors experiencing (or expecting) good times have lower effective risk aversion since their consumption is (or expected to be) further above their slow-moving habit stock. Consequently, in such times the required future returns are low, generating empirically observed predictability of future returns by market indicators of "good" and "bad" times (e.g. price-dividend ratio).

How might we interpret our contradictory imputation? As shown earlier, investors appear to transfer their expectations of good economic times onto their expectations of stock market returns. Moreover, expectations of good business conditions also appear to be associated with reduced uncertainty regarding the stock market. Either of these two findings, on its own, would not necessarily be inconsistent with standard asset pricing models, under some assumptions on the structure of information at investors' disposal. However, their co-existence is much more difficult to rationalize within the standard asset-pricing framework. Rather, we seem to observe judgments by "representativeness" among individual investors: a favorable outlook for business conditions is perceived as a pre-condition for more favorable returns and a

more favorable level of risk in the stock market. Consequently, forward-looking measures of the Sharpe ratio are estimated to be strongly procyclical. Although investor portfolio choices do respond in the direction predicted by theory, the strength of these responses is muted. As a result, imputed "coefficients of relative risk aversion" have to absorb the heterogeneity in beliefs, leading to a counter-intuitive relationship between $\gamma$ 's and macroeconomic conditions.

\section{Conclusion}

We use data obtained from a series of Michigan Surveys of Consumer Attitudes to study stock market beliefs and portfolio choices of individual investors. We find that, in forming 
expectations of future returns, investors extrapolate from returns realized over the previous several years. We also find that a more optimistic assessment of future macroeconomic conditions coincides with higher expected returns and lower expected volatility, implying that forward-looking Sharpe ratios are procyclical. These findings are given added credibility by the finding that respondents' equity positions tend to increase with self-reported measures of expected returns and decline with measures of expected volatility. On balance, our empirical results favor the hypothesis of procyclical variation in investor beliefs rather than that of countercyclical variation in risk aversion.

\section{References}

John Ameriks and Stephen P. Zeldes, "How do household portfolio shares vary with age?" mimeo 2001.

Brad M. Barber and Terrance Odean, "Boys will be boys: Gender, overconfidence, and common stock investment," Quarterly Journal of Economics, 116(1), 2001.

Nicholas Barberis, Andrei Shleifer, and Robert Vishny, "A model of investor sentiment," Journal of Financial Economics, 49(3):307-343, 1998.

Sylvia Beyer, "Gender differences in the accuracy of self-evaluations of performance," Journal of Personality and Social Psychology, 59:960-970, 1990.

Wandi Bruine de Bruin, Paul S. Fischbeck, Neil A Stiber, and Baruch Fischhoff, "What Number is "Fifty-Fifty"?: Redistributing Excessive 50\% Responses in Elicited Probabilities," Risk Analysis, 22(4):713-723, 2002.

John Y. Campbell and John H. Cochrane, "By force of habit: A consumption based explanation of aggregate stock market behavior," Journal of Political Economy, 107(2):205-251, 1999.

John Y. Campbell, Andrew Lo, and Craig MacKinlay. The Econometrics of Financial Markets (Princeton University Press, Princeton, NJ), 1997.

Murillo Campello, Long Chen, and Lu Zhang, "Expected Returns, Yield Spreads, and Asset Pricing Tests," mimeo, University of Illinois-Champaign, January 2003.

Nai-Fu Chen, Richard Roll, and Stephen A. Ross, "Economic Forces and the Stock Market" Journal of Business, 59(3):383-403, July 1986.

James Claus and Jacob Thomas, "Equity Premia as Low as Three Percent? Evidence from Analysts' Earnings Forecasts for Domestic and International Stock Markets," Journal of Finance, v. 56(5):1629-66, October 2001. 
John H. Cochrane, "Where is the market going? Uncertain facts and novel theories," Economic Perspectives, 21(6), 1997.

Kent Daniel, David Hirshleifer, Avanidhar Subrahmanyam, "Investor Psychology and Security Market Under- and Overreactions," Journal of Finance, 53(6):1839-85, December 1998.

Jeff Dominitz and Charles F. Manski, "How Should We Measure Consumer Confidence? Journal of Economic Perspectives, 18(2): pp. 51-66, Spring 2004.

Jeff Dominitz and Charles F. Manski, "Measuring and Interpreting Expectations of Equity Returns," mimeo, Northwestern University, February 2005.

Karen E. Dynan, "Habit formation in consumer preferences: Evidence from panel data", American Economic Review, 90(3):391-406, 2000.

Robert Engle, "Risk and Volatility: Econometric Models and Financial Practice", Nobel Memorial Lecture, 2003.

Eugene F. Fama and Kenneth R. French, "Business conditions and expected returns on stocks and bonds," Journal of Financial Economics, 25(1):23-49, November 1989

Eugene F. Fama and Kenneth R. French, “The equity premium,” Journal of Finance, 57(2):63759, April 2002.

William Gebhardt, Charles Lee, and Bhaskaran Swaminathan, "Toward an Implied Cost of Capital," Journal of Accounting Research, v. 39(1):135-76, June 2001.

Simon Gervais and Terrance Odean, "Learning to be overconfident," Review of Financial Studies, 14(1):1-27, Spring 2001.

Amit Goyal and Ivo Welch, "Predicting the Equity Premium With Dividend Ratios," National Bureau of Economic Research Working Paper No. 8788, 2002.

John Graham and Campbel Harvey, "Expectations of equity risk premia, volatility, and asymmetry from a corporate finance perspective," Working Paper, Duke University, 2003.

John R. Graham and Campbell R. Harvey, "Market timing ability and volatility implied in investment newsletters' asset allocation recommendations," Journal of Financial Economics, 42(3):397-421, 1 November 1996.

Martin Halek and Joseph G. Eisenhauer, "Demography of risk aversion," The Journal of Risk and Insurance, 68(1):1-24, 2001.

Lawrence Hamilton, “srd1: How robust is robust regression?” Stata Technical Bulletin 2:21-26.

Lars P. Hansen and Kenneth J. Singleton, "Stochastic consumption, risk aversion, and the temporal behavior of asset returns," Journal of Political Economy, 91:249-265, April 1983.

Lars Peter Hansen and Thomas J. Sargent, “Acknowledging misspecification in macroeconomic theory”, Review of Economic Dynamics, 4(3):519-35, July 2001.

David Hirshleifer, "Investor psychology and asset pricing," Journal of Finance, 56(4):1533-97, August 2001. 
Martin Lettau and Sydney Ludvigson, "Consumption, Aggregate Wealth, and Expected Stock Returns," Journal of Finance, 56(3):815-49, June 2001.

Daniel Kahneman and Amos Tversky, "Prospect theory: An analysis of decisions under risk," Econometrica, 47:263-291, March 1979.

Robert C. Merton, "Lifetime portfolio selection under uncertainty: The continuous time case," Review of Economics and Statistics, 51(3):373-413, 1969.

Terrance Odean, "Volume, volatility, price and profit when all traders are above average," Journal of Finance, 53(6):1887-1934, December 1998.

Paul A. Samuelson, "Lifetime portfolio selection by dynamic stochastic programming," Review of Economics and Statistics, 51(3):239-246, 1969.

Hersh Shefrin, "Do investors expect higher returns from safer stocks than from riskier stocks?" The Journal of Psychology and Financial Markets, 2(4):176-181, 2001.

Robert Shiller, "Measuring bubble expectations and investor confidence," The Journal of Psychology and Financial Markets, 1(1):49-60, 2000.

Amos Tversky and Daniel Kahneman, "Judgment under uncertainty: Heuristics and biases," Science, 185(4157):1124-1131, 1974.

Luis M. Viceira, "Optimal portfolio choice for long-horizon investors with nontradable labor income," Journal of Finance, 56(2):433-470, 2001.

Annette Vissing-Jorgensen, "Perspectives on behavioral finance: Does irrationality disappear with wealth? Evidence from expectations and actions," NBER Macroeconomics Annual, June 2003. 
Figure 1

\section{Actual vs. Recalled Average S\&P 500 Returns, Previous 10 yrs}

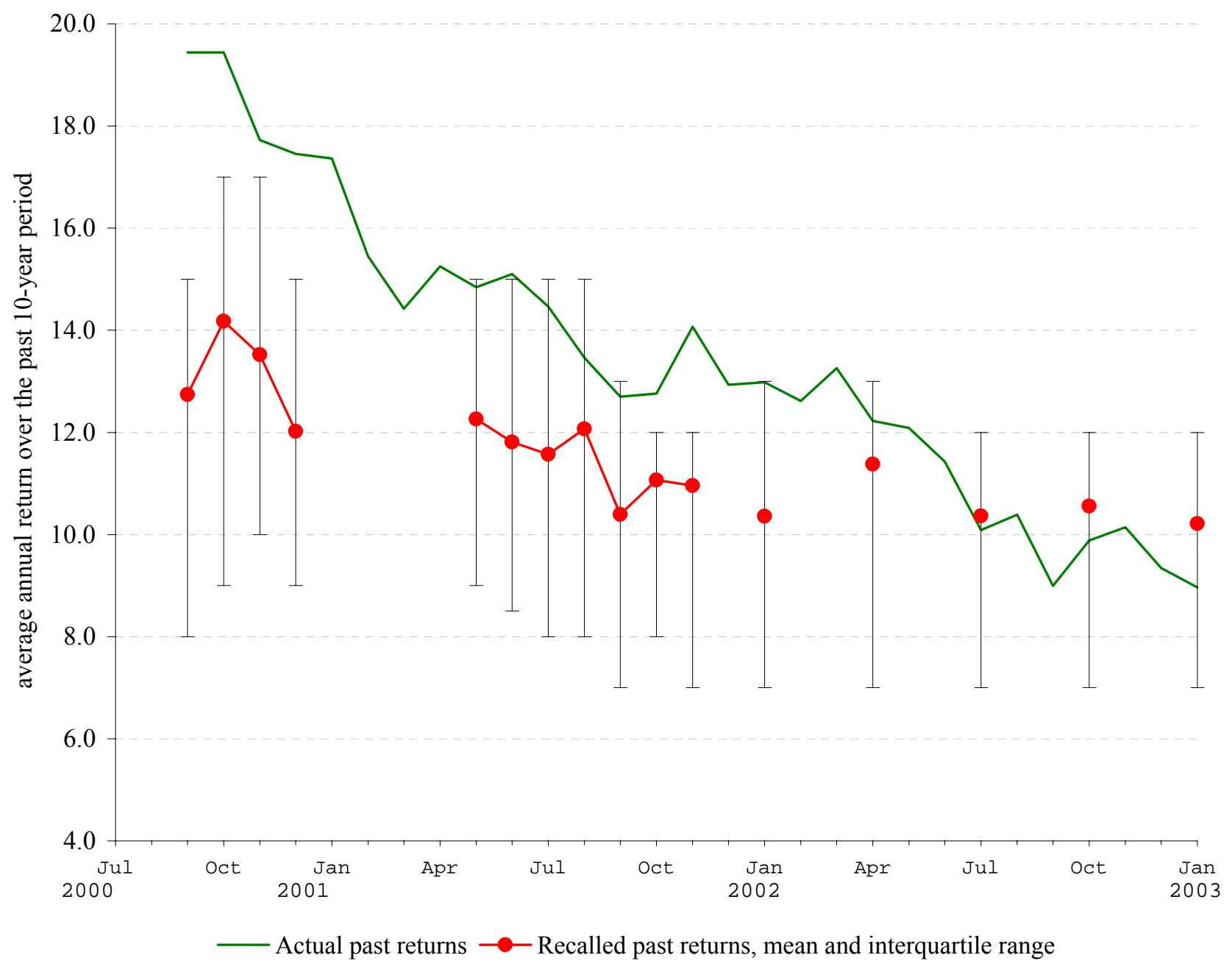

Actual S\&P 500 returns are defined as a geometric average of total returns on SPTR index over the 120-month period prior to the survey month.

In the October 2004 survey, the questions on investor assessment of past 10-year S\&P500 returns was reintroduced. The mean response was 9.6 percent, with the interquartile range covering the $[5,10]$ interval. By comparison, the actual realized S\&P500 return over the preceding 10 -year period was 11 percent. 


\section{Figure 2A}

\section{Expected Returns vs. Past Returns}

Michigan Survey, survey means

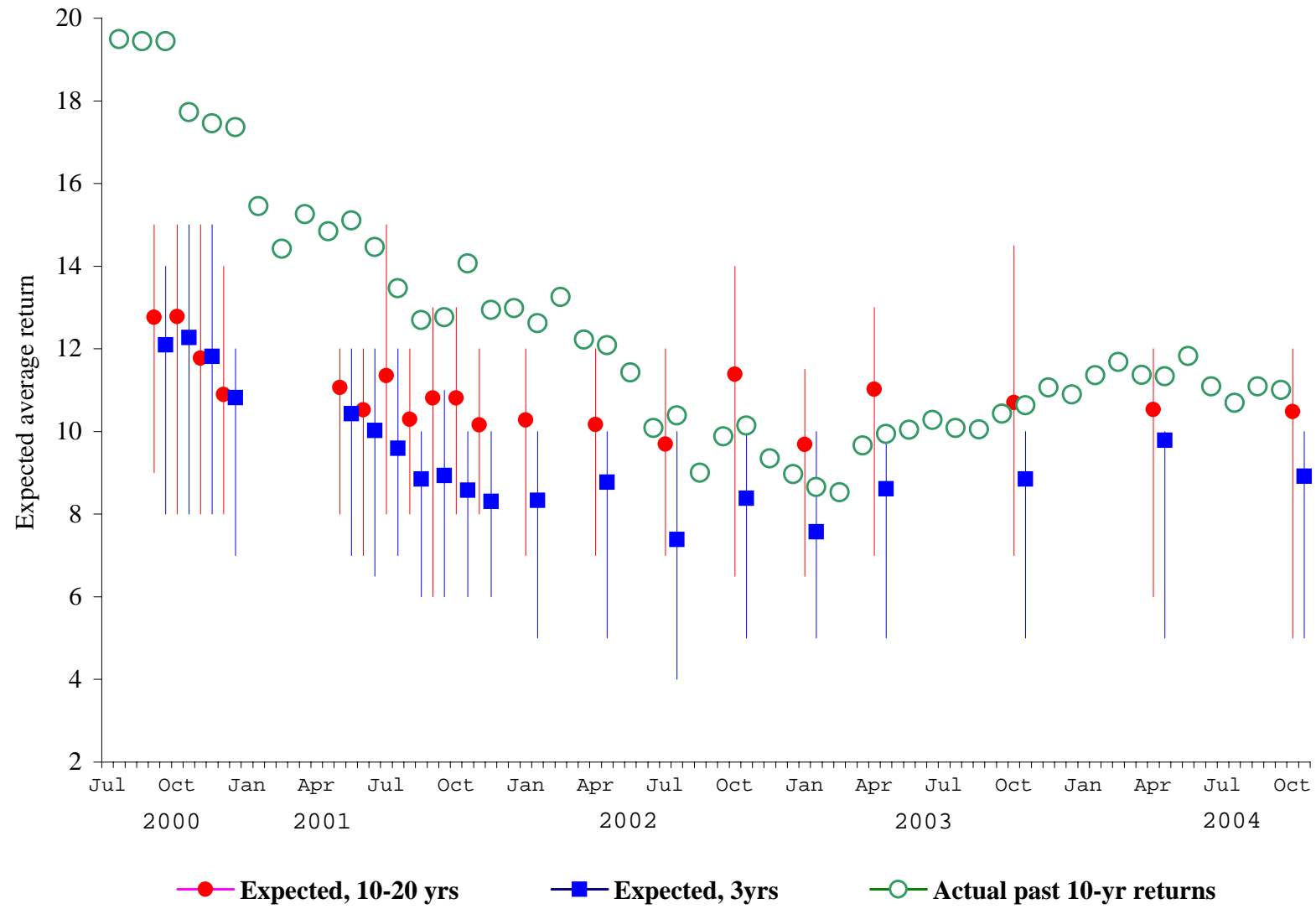

The means of expected long- and medium-term returns of Michigan survey respondents are plotted against realized average annual returns on the S\&P500 total returns index (SPTR) over the 10-year period preceding the survey date. The vertical bars represent the interquartile range of the responses. 
Figure 2B

Time Series of Medium Term (2-3 yr) Expected Returns, by Investor Wealth Michigan Survey, survey means

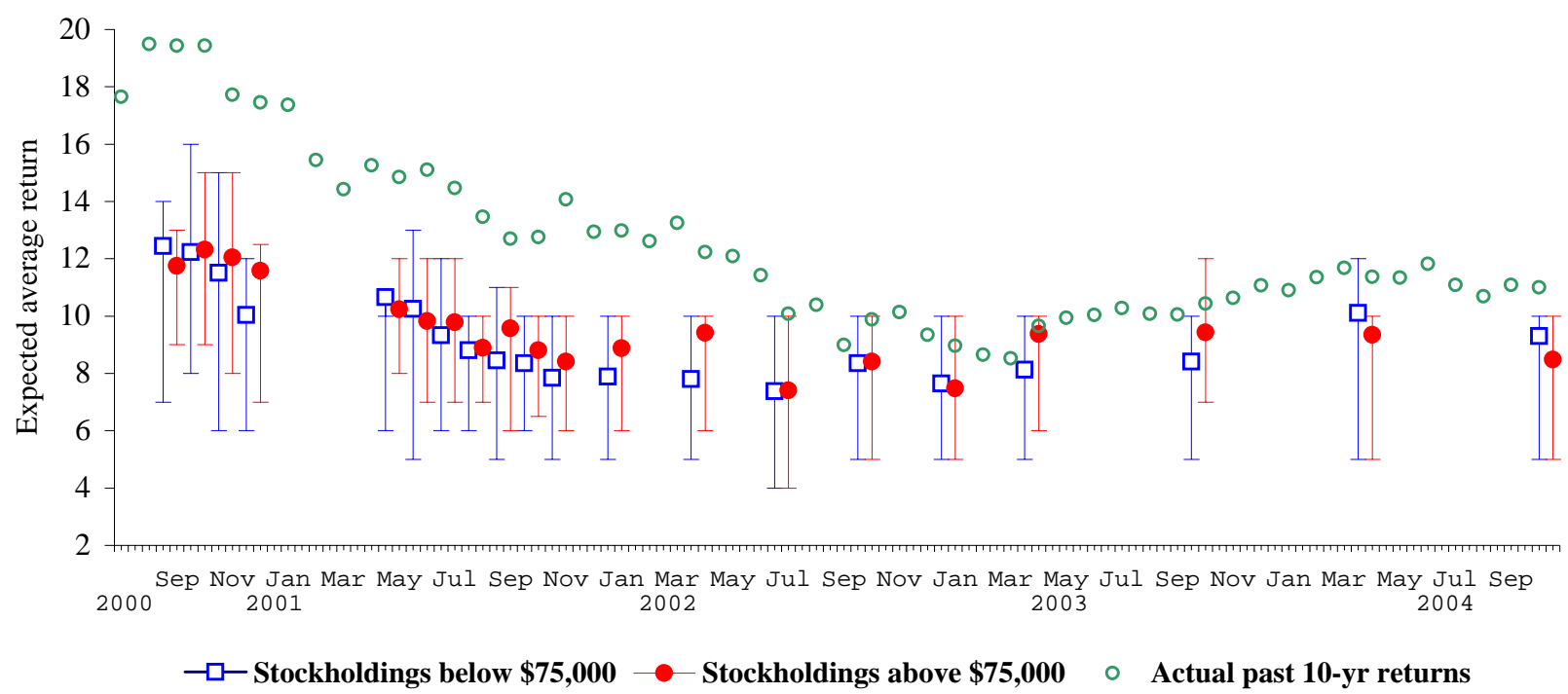

Figure 2C

Time Series of Medium Term (2-3 yr) Expected Returns, by Decisionmaker Status Michigan Survey, survey means

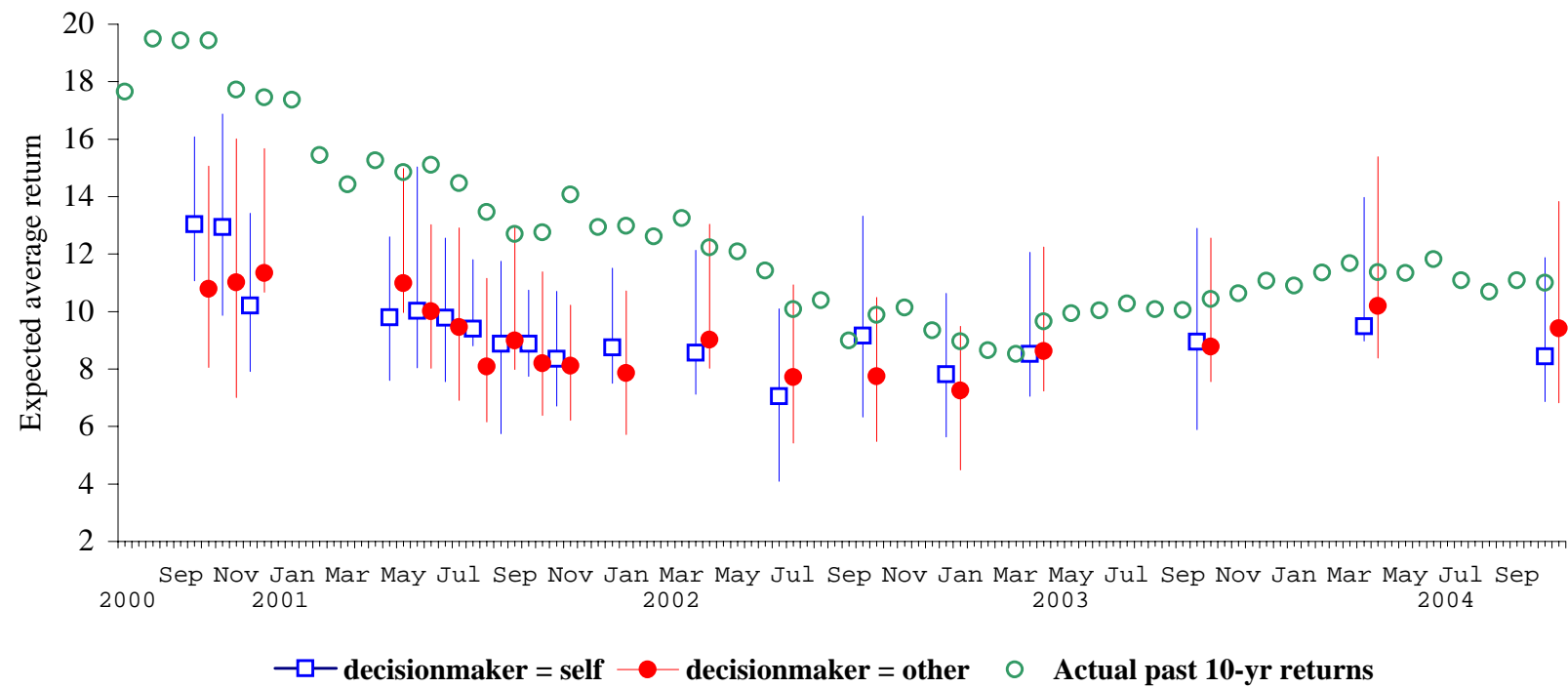


Figure 3

Measures of Expected Near-term Stock Market Performance

Michigan and Gallup Survey Means

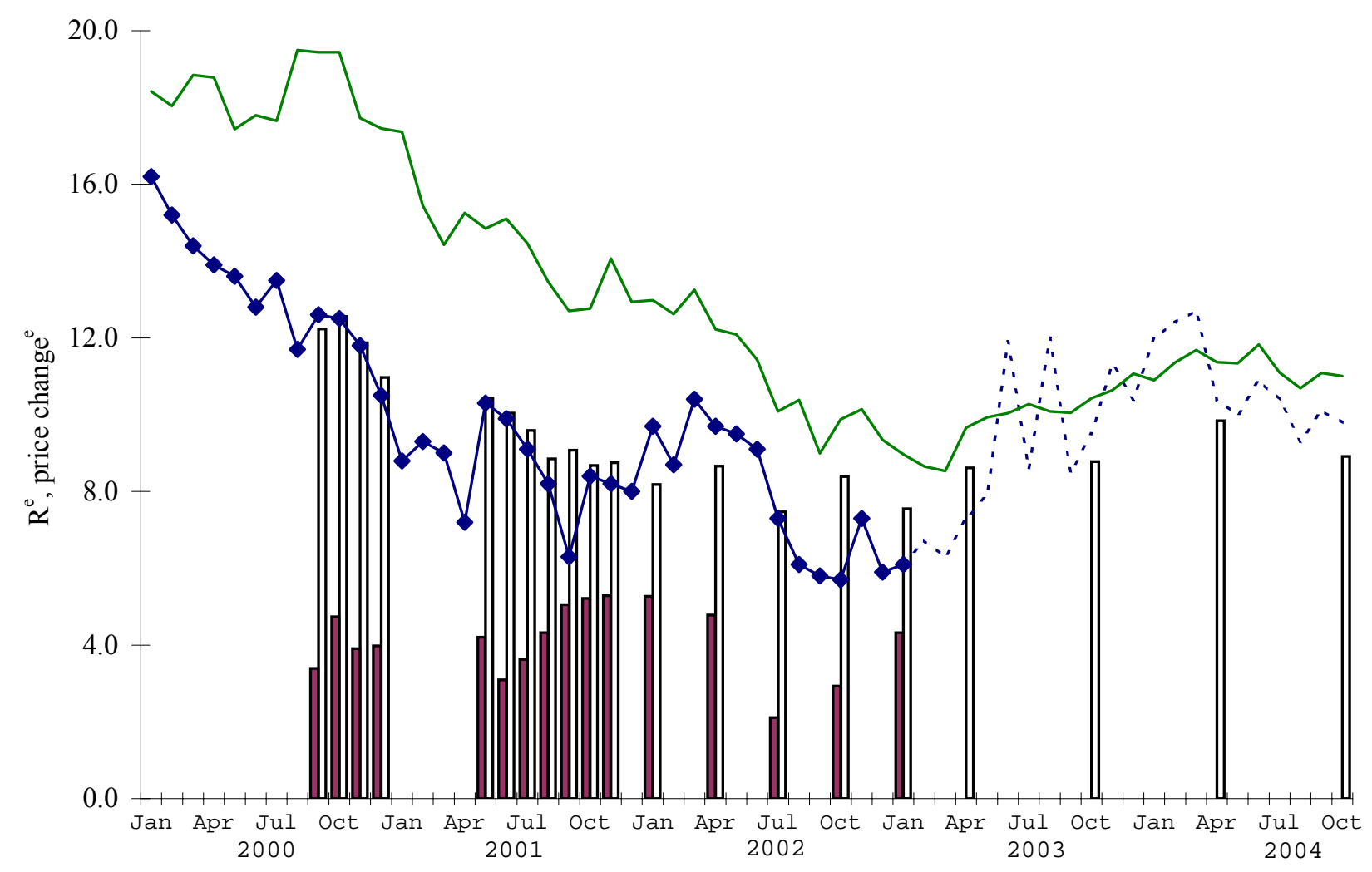

Prior to February 2003, the UBS/Gallup series is derived from the question on expected 12-month market returns. After this question was discontinued, we augmented the series with the mean response to the Gallup expected 12-month own returns question (dashed unmarked line). 
Figure 4

\section{Ex Ante Expected Returns from Survey Data and CAY}

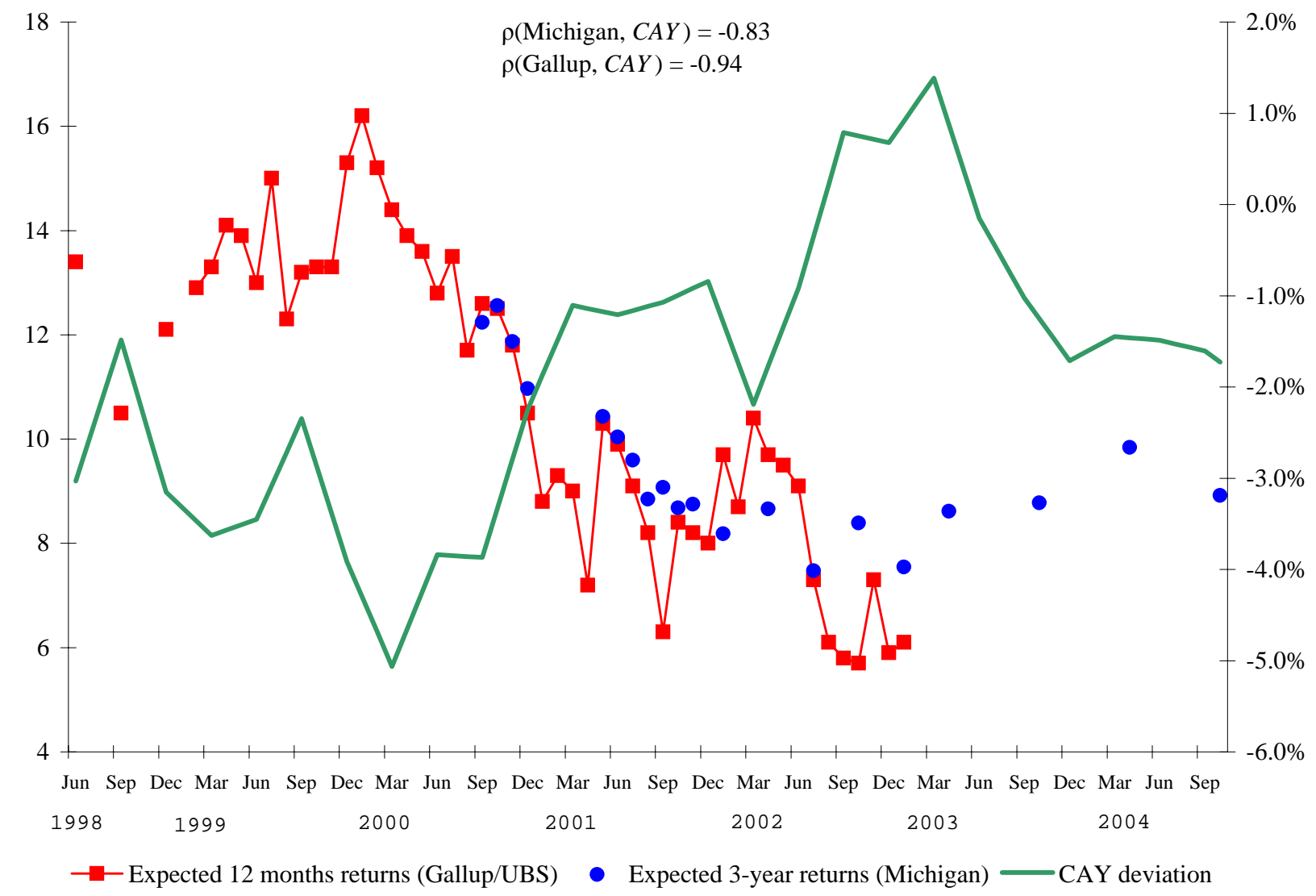

The means of expected returns from survey responses (Michigan and Gallup/UBS) are plotted against the trend deviation of $C A Y$ series constructed as in Lettau and Ludvigson (2003) and updated to cover the period through Q4, 2004. Since the CAY series are quarterly, the monthly series shown in this figure are constructed by linearly interpolating between quarterly nodes. Both reported correlation coefficients are computed for the subsample of matching data points. 
Figure 5

Investor Assessments of Volaility in Expected Average Returns

\section{Probabilistic questions regarding future average returns}

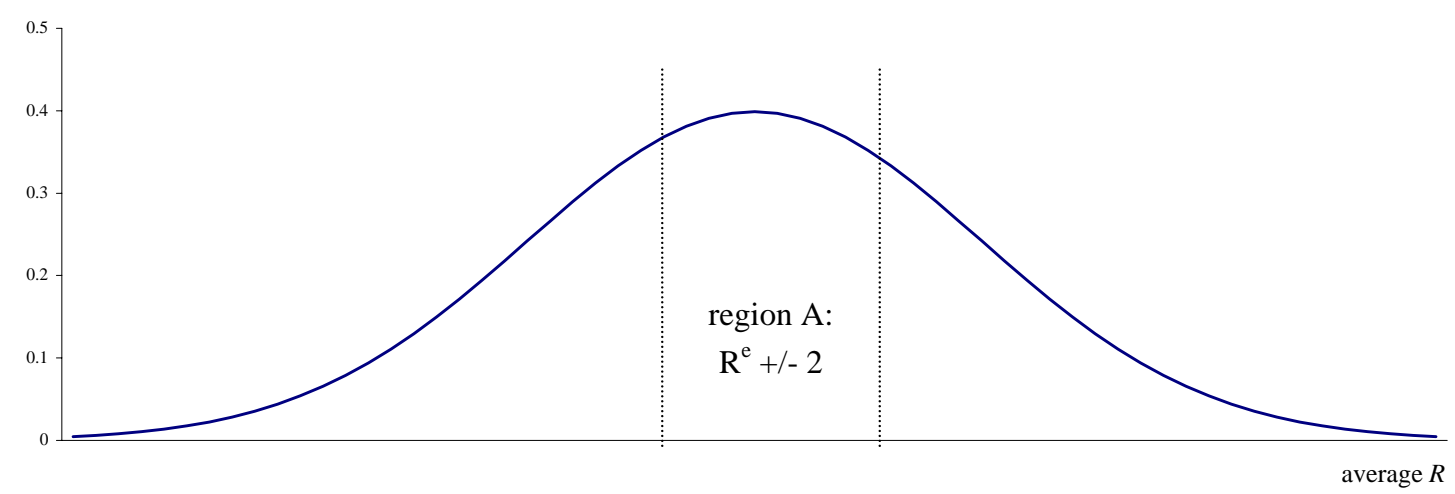

Distribution of Prob $\left[\mathbf{R}^{\mathrm{e}}-2<\mathbf{R}<\mathbf{R}^{\mathrm{e}}+2\right]$

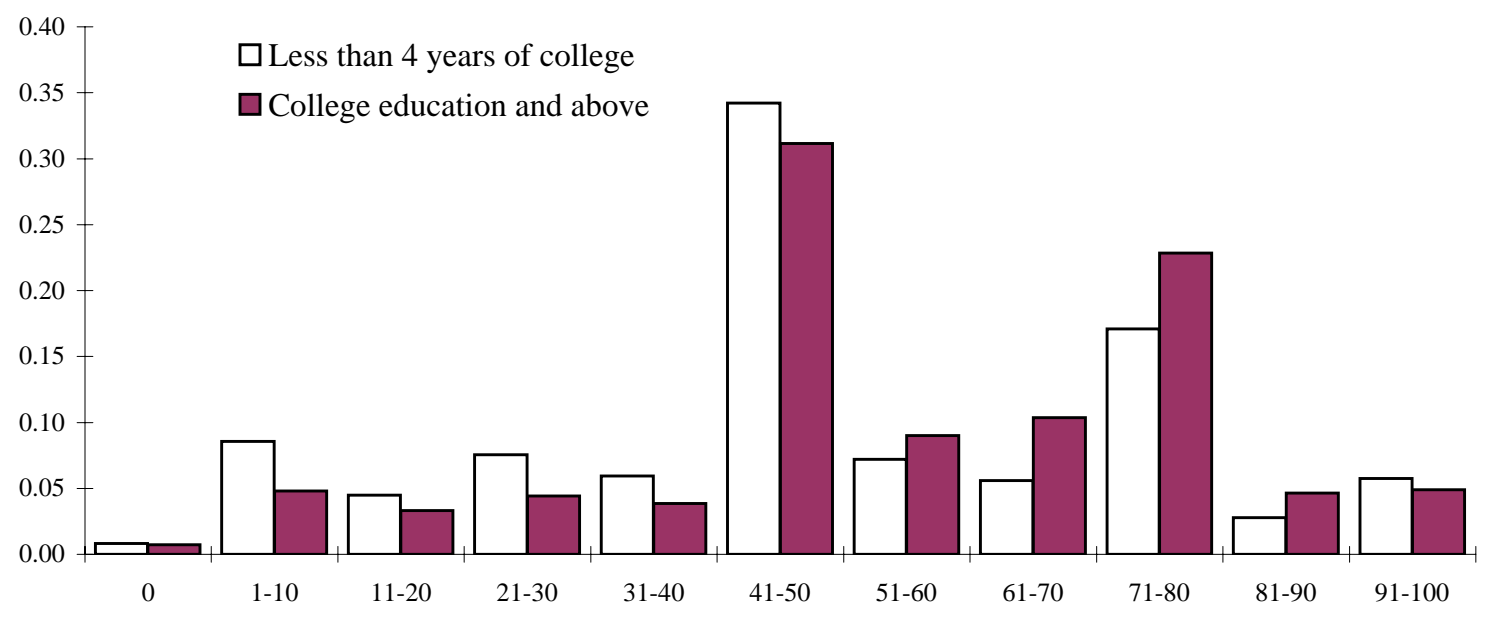

Distribution of Raw Replies and Imputed Ex Ante Volatility of Long-Term Average Market Returns

\begin{tabular}{lccccccc} 
& $\mathrm{N}$ & Mean & 10th pct & $25 \mathrm{pct}$ & Median & 75th pct & 90th pct \\
\hline uncertainty & 2,552 & 45.0 & 20 & 25 & 50 & 50 & 80 \\
$\sigma_{\mathrm{c}}{ }^{\#}$ & 2,552 & 4.62 & 1.56 & 1.73 & 2.96 & 2.96 & 7.88 \\
\hline
\end{tabular}

uncertainty is defined as the complement of probability mass assigned to region A in the upper panel. This meas has a direct and one-to-one relatonship to imputed standard deviation under the assumption of asymptotic normali

\# imputed from raw responses to question about $\operatorname{prob}\left(\mathrm{R}^{\mathrm{e}}-2<R<\mathrm{R}^{\mathrm{e}}+2\right)$ using equation (2), pg 18.

Based on survey data from September 2000 through October 2004. 


\section{Table 1. Determinants of Recall Error}

Recall Error:

$\lfloor$ past 10-year return - recalled return $\mid$
Fail to reply to the past return question $(1=$ yes $)$

\begin{tabular}{|c|c|c|c|}
\hline Regressors & $(1)$ & (2) & $(3)$ \\
\hline "Good" understanding of questions & $\begin{array}{c}-1.710 \\
(2.8)\end{array}$ & $\begin{array}{c}-1.699 \\
(2.9)\end{array}$ & $\begin{array}{c}-0.204 \\
(0.9)\end{array}$ \\
\hline "Cooperative" attitude & $\begin{array}{c}-0.405 \\
(0.6)\end{array}$ & $\begin{array}{c}-0.586 \\
(0.9)\end{array}$ & $\begin{array}{c}-0.240 \\
(0.9)\end{array}$ \\
\hline Education (some college) & $\begin{array}{c}-0.148 \\
(0.6)\end{array}$ & $\begin{array}{c}-0.113 \\
(0.4)\end{array}$ & $\begin{array}{c}-0.213 \\
(2.0)\end{array}$ \\
\hline Education (college) & $\begin{array}{c}-0.828 \\
(3.5)\end{array}$ & $\begin{array}{c}-0.953 \\
(4.0)\end{array}$ & $\begin{array}{c}-0.285 \\
(2.9)\end{array}$ \\
\hline Education (graduate) & $\begin{array}{c}-0.695 \\
(2.8)\end{array}$ & $\begin{array}{c}-0.795 \\
(3.1)\end{array}$ & $\begin{array}{c}-0.529 \\
(4.6)\end{array}$ \\
\hline Age $35-44$ & $\begin{array}{c}-0.600 \\
(2.6)\end{array}$ & $\begin{array}{c}-0.670 \\
(2.8)\end{array}$ & $\begin{array}{c}-0.103 \\
(1.0)\end{array}$ \\
\hline Age $45-54$ & $\begin{array}{c}-0.517 \\
(2.1)\end{array}$ & $\begin{array}{c}-0.443 \\
(1.7)\end{array}$ & $\begin{array}{c}0.011 \\
(0.1)\end{array}$ \\
\hline Age 55-64 & $\begin{array}{c}-0.009 \\
(0.0)\end{array}$ & $\begin{array}{c}0.100 \\
(0.3)\end{array}$ & $\begin{array}{c}0.117 \\
(0.9)\end{array}$ \\
\hline Age $65-97$ & $\begin{array}{c}0.014 \\
(0.0)\end{array}$ & $\begin{array}{c}0.023 \\
(0.1)\end{array}$ & $\begin{array}{c}0.359 \\
(2.4)\end{array}$ \\
\hline Log invstmt experience yrs & $\begin{array}{c}0.118 \\
(1.0)\end{array}$ & $\begin{array}{c}0.201 \\
(1.6)\end{array}$ & $\begin{array}{c}-0.013 \\
(0.2)\end{array}$ \\
\hline Gender $(1=$ male $)$ & $\begin{array}{c}-0.429 \\
(2.7)\end{array}$ & $\begin{array}{c}-0.357 \\
(2.2)\end{array}$ & $\begin{array}{c}-0.384 \\
(5.4)\end{array}$ \\
\hline Decisionmaker dummy & $\begin{array}{c}-0.597 \\
(3.8)\end{array}$ & $\begin{array}{c}-0.532 \\
(3.3)\end{array}$ & $\begin{array}{c}-0.149 \\
(2.1)\end{array}$ \\
\hline Stock portfolio value $(\$ 25 \mathrm{k}-\$ 75 \mathrm{k})$ & $\begin{array}{c}-0.572 \\
(2.5)\end{array}$ & $\begin{array}{c}-0.542 \\
(2.3)\end{array}$ & $\begin{array}{c}-0.113 \\
(1.1)\end{array}$ \\
\hline Stock portfolio value $(\$ 75 \mathrm{k}-\$ 200 \mathrm{k})$ & $\begin{array}{c}-0.903 \\
(3.6)\end{array}$ & $\begin{array}{c}-1.049 \\
(4.1)\end{array}$ & $\begin{array}{c}-0.239 \\
(2.1)\end{array}$ \\
\hline Stock portfolio value (> \$200k) & $\begin{array}{c}-1.649 \\
(5.9)\end{array}$ & $\begin{array}{c}-1.709 \\
(5.9)\end{array}$ & $\begin{array}{c}-0.187 \\
(1.5)\end{array}$ \\
\hline Constant term & 10.704 & 8.896 & -0.034 \\
\hline Time dummies & Yes & Yes & Yes \\
\hline $\mathrm{N}$ (obs.) & 1,850 & 1,581 & 2,134 \\
\hline Measure of fit (pseudo- $\mathrm{R}^{2}$ ) & 0.157 & 0.108 & 0.062 \\
\hline
\end{tabular}

$t$-statistics are in parentheses.

Sample period: (1) and (3) are based on September 2000 - January, 2003 and the October, 2004 surveys.

(2) drops observations from surveys conducted in 2000.

(1) and (2) are estimated using robust regression algorithm (iterative GLS of Hamilton, 1991), while (3) is estimated using a probit model. 


\section{Table 2. Tests of Extrapolation in Investors' Expectations of Stock Market Returns}

\section{Panel A}

Regressors

Past 3-year S\&P return

Past 3-year S\&P return, smoothed base

Recall error (recalled - actual 10-yr return)

Past 3-month S\&P return

Past 10-year S\&P return

Constant term

$\mathrm{N}$ (obs.)

Measure of fit $\left(\operatorname{adj}-\mathrm{R}^{2}\right)$

\section{Dependent Variable: medium-term expected return (2-3 years)}

(1)

0.108

(12.7)
(2)

(3)

(4)

(5)

0.192

(13.4) (20.1)

$\begin{array}{lll}0.281 & 0.287 & 0.246\end{array}$

$\begin{array}{lll}(21.2) & (21.8) & \text { (12.4) }\end{array}$

$\begin{array}{lll}-0.001 & 0.007 & 0.002\end{array}$

$\begin{array}{lll}(0.1) & (0.7) & (0.1)\end{array}$

0.626

(21.6)

$0.875 \quad 9.203$

8.357

8.347

9.054

1,934

1,016

2,732

2,732

1,934

0.274

\section{Panel B}

Regressors

Past 3-year S\&P return

Past 3-year S\&P return, smoothed base

Recall error (recalled - actual 10-yr return)

Past 3-month S\&P return

Past 10-year S\&P return

Constant term

$\mathrm{N}$ (obs.)

Measure of fit $\left(\operatorname{adj}-\mathrm{R}^{2}\right)$

Dependent Variable: long-term expected return (10-20 years)

(1)

0.046

(5.0)
(2)

(3)

(4)

(5)

$t$-statistics are in parentheses

Sample period: September 2000-October, 2004 in (1)-(2); September 2000-January, 2003 and October, 2004 in (3-5). Data quality filter: remove respondents with incomplete replies, those rated as having "poor understanding of questions" or "hostile attitude", and those providing 50/50 replies to all probabilistic questions.

(1) - (4) are estimated on the entire sample, while (5) is limited to households with more than $\$ 75,000$ in stock holdings.

(1) - (5) are estimated using robust regression algorithm (iterative GLS of Hamilton, 1991). Qualitatively similar results are obtained with quantile (median) regression estimation, and with trunctation of extreme percentile responses.

All returns variable (aside from 3-month returns) are annualized returns. 


\section{Table 3. Determinants of Investors' Expectations of Stock Market Returns}

\begin{tabular}{|c|c|c|c|c|}
\hline \multirow[t]{2}{*}{ Dependent variable: } & \multicolumn{2}{|c|}{$\begin{array}{c}\text { long-term } \\
\text { expected return (10-20 years) }\end{array}$} & \multicolumn{2}{|c|}{$\begin{array}{c}\text { medium-term } \\
\text { expected return (2-3 years) } \\
\end{array}$} \\
\hline & (1) & $(2)$ & (3) & (4) \\
\hline Regressors & Coef. & Coef. & Coef. & Coef. \\
\hline Good times, next 5 years & $\begin{array}{c}0.192 \\
(3.4)\end{array}$ & $\begin{array}{c}0.127 \\
(2.2)\end{array}$ & $\begin{array}{c}0.379 \\
(7.2)\end{array}$ & $\begin{array}{c}0.259 \\
(5.1)\end{array}$ \\
\hline Better conditions, next 12 months & $\begin{array}{c}0.177 \\
(2.6)\end{array}$ & $\begin{array}{c}0.250 \\
(3.7)\end{array}$ & $\begin{array}{c}0.061 \\
(1.0)\end{array}$ & $\begin{array}{c}0.191 \\
(3.1)\end{array}$ \\
\hline Past 10-year S\&P return & & $\begin{array}{c}0.183 \\
(6.3)\end{array}$ & & $\begin{array}{l}0.349 \\
(13.4)\end{array}$ \\
\hline Gender (1=male $)$ & $\begin{array}{c}0.191 \\
(1.1)\end{array}$ & $\begin{array}{c}0.197 \\
(1.1)\end{array}$ & $\begin{array}{c}0.691 \\
(4.2)\end{array}$ & $\begin{array}{c}0.733 \\
(4.7)\end{array}$ \\
\hline Log invstmt experience yrs & $\begin{array}{c}-0.068 \\
(0.6)\end{array}$ & $\begin{array}{c}-0.040 \\
(0.3)\end{array}$ & $\begin{array}{c}0.020 \\
(0.2)\end{array}$ & $\begin{array}{c}0.092 \\
(0.8)\end{array}$ \\
\hline Age controls & Yes & Yes & Yes & Yes \\
\hline Education controls & Yes & Yes & Yes & Yes \\
\hline Constant & 9.187 & 6.702 & 7.301 & 2.428 \\
\hline $\mathrm{N}$ (obs.) & 2,607 & 2,607 & 2,607 & 2,607 \\
\hline Measure of fit (adj- $R^{2}$ ) & 0.015 & 0.030 & 0.037 & 0.102 \\
\hline
\end{tabular}

$t$-statistics are in parentheses.

Sample period: September 2000-October, 2004.

All regressions are estimated using the robust regression method of Hamilton (1991) which mutes the influence of outlier responses. The two variables describing future macroeconomic conditions take on values in the [-2,2] range with positive values indicating good (better) expectations.

The constant term in each of the regressions represents the average stock market return expectations of a female respondent with one year of investment experience who is less than 35 years of age, did not attend college, and who holds a "neutral" view regarding future macroeconomic conditions.

Age and education dummies were included in each regression, but their coefficeint estimates are suppressed for brevity. In all four specifications, the joint hypothesis of no education effects could not be rejected at the 5 percent level of significance. Age effects were jointly significant in explaining long-term expected returns. 


\section{Table 4. Decomposition of Macro Expectations in Regressions of Expected Returns}

\begin{tabular}{|c|c|c|c|c|}
\hline \multirow[t]{2}{*}{ Dependent variable: } & \multicolumn{2}{|c|}{$\begin{array}{c}\text { long-term } \\
\text { expected return (10-20 years) }\end{array}$} & \multicolumn{2}{|c|}{$\begin{array}{c}\text { medium-term } \\
\text { expected return (2-3 years) }\end{array}$} \\
\hline & $(1)$ & $(2)$ & (3) & $\underline{(4)}$ \\
\hline Regressors & Coef. & Coef. & Coef. & Coef. \\
\hline Good times, next 5 years, deviation from mean & $\begin{array}{c}0.153 \\
(2.7)\end{array}$ & $\begin{array}{c}0.131 \\
(2.3)\end{array}$ & $\begin{array}{c}0.298 \\
(5.7)\end{array}$ & $\begin{array}{c}0.262 \\
(5.1)\end{array}$ \\
\hline Good times, next 5 years, survey mean & $\begin{array}{c}1.223 \\
(4.4)\end{array}$ & $\begin{array}{c}-0.325 \\
(0.8)\end{array}$ & $\begin{array}{l}2.553 \\
(10.0)\end{array}$ & $\begin{array}{l}-0.087 \\
(0.2)\end{array}$ \\
\hline Better conditions, next 12 months & $\begin{array}{c}0.200 \\
(2.9)\end{array}$ & $\begin{array}{c}0.255 \\
(3.7)\end{array}$ & $\begin{array}{c}0.102 \\
(1.6)\end{array}$ & $\begin{array}{c}0.195 \\
(3.2)\end{array}$ \\
\hline Past 10 -year $\mathrm{S} \& \mathrm{P}$ return & & $\begin{array}{c}0.218 \\
(4.9)\end{array}$ & & $\begin{array}{c}0.376 \\
(9.5)\end{array}$ \\
\hline Gender $(1=$ male $)$ & $\begin{array}{c}0.194 \\
(1.1)\end{array}$ & $\begin{array}{c}0.189 \\
(1.1)\end{array}$ & $\begin{array}{c}0.757 \\
(4.7)\end{array}$ & $\begin{array}{c}0.726 \\
(4.6)\end{array}$ \\
\hline Log invstmt experience yrs & $\begin{array}{c}-0.045 \\
(0.4)\end{array}$ & $\begin{array}{c}-0.043 \\
(0.7)\end{array}$ & $\begin{array}{c}0.078 \\
(0.7)\end{array}$ & $\begin{array}{c}0.089 \\
(0.8)\end{array}$ \\
\hline Age controls & Yes & Yes & Yes & Yes \\
\hline Education controls & Yes & Yes & Yes & Yes \\
\hline Constant & 8.573 & 6.506 & 5.760 & 2.284 \\
\hline $\mathrm{N}$ (obs.) & 2,607 & 2,607 & 2,607 & 2,607 \\
\hline Measure of fit (adj- $\left.R^{2}\right)$ & 0.020 & 0.030 & 0.068 & 0.102 \\
\hline
\end{tabular}

$t$-statistics are in parentheses.

Sample period: September 2000-October, 2004.

All regressions are estimated using the robust regression method of Hamilton (1991) which mutes the influence of outlier responses. The two variables describing future macroeconomic conditions take on values in the $[-2,2]$ range with positive values indicating good (better) expectations. The deviation of Good times, next 5 years, is defined for each respondent relative to the sample mean of Good times, next 5 years on a given survey date. 
Table 5

\section{Determinants of Ex Ante Volatility of Long-Term Average Market Returns}

\section{Dependent Variable:}

Uncertainty $=100-\operatorname{prob}\left(R^{\mathrm{e}}-2<R<R^{\mathrm{e}}+2\right)$

$\underline{\text { Tobit regressions }}$

\begin{tabular}{|c|c|c|c|}
\hline Regressors & $\frac{(1)}{\text { Coef. }}$ & $\frac{(2)}{\text { Coef. }}$ & $\frac{(3)}{\text { Coef. }}$ \\
\hline Good times, next 5 years & $\begin{array}{c}-1.47 \\
(4.6)\end{array}$ & $\begin{array}{l}-0.95 \\
(-2.9)\end{array}$ & $\begin{array}{c}-0.83 \\
(2.3)\end{array}$ \\
\hline Better conditions, next 12 months & $\begin{array}{c}-1.01 \\
(2.6)\end{array}$ & $\begin{array}{c}-0.60 \\
(1.5)\end{array}$ & $\begin{array}{c}-0.61 \\
(1.4)\end{array}$ \\
\hline $\mid R^{\mathrm{e}}-$ Recalled S\&P returns $\mid$ & & & $\begin{array}{l}0.69 \\
-6.00\end{array}$ \\
\hline Expect income to outpace inflation, next 5 yrs (pct chance) & & $\begin{array}{c}-0.09 \\
(5.3)\end{array}$ & $\begin{array}{c}-0.09 \\
(4.4)\end{array}$ \\
\hline House value appreciated last year & & $\begin{array}{c}-2.13 \\
(1.7)\end{array}$ & $\begin{array}{c}-2.46 \\
(1.7)\end{array}$ \\
\hline House value depreciated last year & & $\begin{array}{l}0.14 \\
(0.5)\end{array}$ & $\begin{array}{l}2.03 \\
(0.6)\end{array}$ \\
\hline Decision maker dummy (yes $=1)$ & & $\begin{array}{c}-2.34 \\
(2.3)\end{array}$ & $\begin{array}{c}-2.02 \\
(1.8)\end{array}$ \\
\hline Years of invstmt experience $(\ln )$ & & $\begin{array}{c}-1.30 \\
(1.8)\end{array}$ & $\begin{array}{c}-1.56 \\
(1.9)\end{array}$ \\
\hline Gender $($ male $=1)$ & & $\begin{array}{c}-5.02 \\
(4.9)\end{array}$ & $\begin{array}{c}-5.19 \\
(4.4)\end{array}$ \\
\hline Age (35-44) & & $\begin{array}{c}-1.45 \\
(1.0)\end{array}$ & $\begin{array}{c}-3.49 \\
(2.1)\end{array}$ \\
\hline Age (45-54) & & $\begin{array}{c}-2.15 \\
(1.4)\end{array}$ & $\begin{array}{c}-5.06 \\
(2.8)\end{array}$ \\
\hline Age (55-64) & & $\begin{array}{c}-1.79 \\
(1.0)\end{array}$ & $\begin{array}{c}-2.94 \\
(1.4)\end{array}$ \\
\hline Age (65-97) & & $\begin{array}{c}-1.36 \\
(0.6)\end{array}$ & $\begin{array}{c}-3.59 \\
(1.4)\end{array}$ \\
\hline Education (some college) & & $\begin{array}{c}-1.07 \\
(0.7)\end{array}$ & $\begin{array}{l}0.88 \\
(0.5)\end{array}$ \\
\hline Education (college) & & $\begin{array}{c}-5.29 \\
(3.6)\end{array}$ & $\begin{array}{c}-4.46 \\
(2.6)\end{array}$ \\
\hline Education (graduate) & & $\begin{array}{c}-5.77 \\
(3.7)\end{array}$ & $\begin{array}{c}-4.49 \\
(2.4)\end{array}$ \\
\hline Constant & 54.59 & 64.72 & 63.37 \\
\hline Time Dummies & Yes & Yes & Yes \\
\hline $\mathrm{N}($ obs. $)$ & 2,594 & 2,434 & 1,704 \\
\hline $\mathrm{N}$ censored at 0 & 126 & 120 & 89 \\
\hline $\mathrm{N}$ censored at 100 & 20 & 19 & 11 \\
\hline Measure of fit (pseudo- $\mathrm{R}^{2}$ ) & 0.004 & 0.010 & 0.015 \\
\hline
\end{tabular}

$t$-statistics are in parentheses.

The dependent variable is defined as the complement of raw responses to the question about the probability of being in a 2 percentage point band around expected 10-year average return.

Sample period for (1) and (2): September, 2000-October, 2004.

Sample period for (3): September, 2000-January 2003 and the October 2004 survey.

All regressions are estimated on survey data after removing respondents failing the data quality filter. 


\section{Table 6 \\ Effect of Investor Expectations on Portfolio Choice}

Dependent Variable: portfolio fraction in stocks

\begin{tabular}{|c|c|c|c|}
\hline Regressors & $\begin{array}{l}\frac{(1)}{\text { ordered logit }} \\
\text { Coef. }\end{array}$ & $\begin{array}{l}\text { ion spec } \\
\frac{(2)}{\text { OLS }} \\
\text { Coef. }\end{array}$ & $\begin{array}{l}\frac{(3)}{\text { OLS }} \\
\text { Coef. }\end{array}$ \\
\hline Expected excess returns $\left(R_{\mathrm{i}}^{\mathrm{e}}-R^{\mathrm{f}}\right.$, in pct $)$ & $\begin{array}{l}5.73 \\
(4.3)\end{array}$ & $\begin{array}{l}0.82 \\
(4.4)\end{array}$ & $\begin{array}{l}0.87 \\
(4.5)\end{array}$ \\
\hline Expected volatility* (in pct) & $\begin{array}{c}-1.20 \\
(6.5)\end{array}$ & $\begin{array}{c}-0.18 \\
(6.9)\end{array}$ & $\begin{array}{c}-0.14 \\
(5.4)\end{array}$ \\
\hline Years of invstmt experience (ln) & & & $\begin{array}{l}0.07 \\
(7.1)\end{array}$ \\
\hline Household income (ln) & & & $\begin{array}{c}-0.01 \\
(0.5)\end{array}$ \\
\hline Age (35-44) & & & $\begin{array}{c}-0.03 \\
(1.7)\end{array}$ \\
\hline Age (45-54) & & & $\begin{array}{c}-0.04 \\
(2.2)\end{array}$ \\
\hline Age (55-64) & & & $\begin{array}{c}-0.03 \\
(1.1)\end{array}$ \\
\hline Age (65-97) & & & $\begin{array}{c}-0.03 \\
(0.9)\end{array}$ \\
\hline Education (some college) & & & $\begin{array}{l}0.02 \\
(0.9)\end{array}$ \\
\hline Education (college) & & & $\begin{array}{l}0.07 \\
(3.9)\end{array}$ \\
\hline Education (graduate) & & & $\begin{array}{l}0.08 \\
(4.2)\end{array}$ \\
\hline Time Dummies & Yes & Yes & Yes \\
\hline Constant & & 0.41 & 0.30 \\
\hline $\mathrm{N}$ (obs.) & 1,866 & 1,866 & 1,725 \\
\hline Measure of fit (adj- $R^{2} /$ pseudo- $R^{2}$ ) & 0.02 & 0.05 & 0.09 \\
\hline
\end{tabular}

$t$-statistics are in parentheses.

Sample period: July, 2001-October, 2004.

Data quality filter: remove respondents with incomplete replies, those rated as having "poor understanding of questions" or "hostile attitude", and those providing 50/50 replies to all probabilistic questions.

* In (1) - (3) expected volailtity is proxied by Within $2^{c}$ 
Table 7

\section{Effect of Investor Expectations on Portfolio Choice (log specification)}

\section{Dependent Variable: log portfolio fraction in stocks}

\begin{tabular}{|c|c|c|c|}
\hline Regressors & $\begin{array}{c}\frac{(1)}{\text { Market measure of } R_{-}^{\mathrm{f}}} \\
\text { OLS } \\
\text { Coef. } \\
\end{array}$ & $\begin{array}{c}\frac{(2)}{\text { Market measure of } R_{-}^{\mathrm{f}}} \\
\text { OLS } \\
\text { Coef. } \\
\end{array}$ & $\begin{array}{c}\frac{(3)}{\text { Own measure of } R_{-}^{\mathrm{f}}} \\
\text { OLS } \\
\text { Coef. } \\
\end{array}$ \\
\hline Log expected excess returns $\left(R_{\mathrm{i}}^{\mathrm{e}}-R^{\mathrm{f}}\right.$, in pct $)$ & $\begin{array}{c}0.08 \\
(3.0)\end{array}$ & & \\
\hline Log expected returns $\left(R_{\mathrm{i}}{ }^{\mathrm{e}}\right)$ & & $\begin{array}{l}0.25 \\
(4.9)\end{array}$ & \\
\hline Log expected excess returns $\left(R_{\mathrm{i}}^{\mathrm{e}}-R_{\mathrm{i}}{ }^{\mathrm{f}}\right)$ & & & $\begin{array}{l}0.13 \\
(2.0)\end{array}$ \\
\hline Log expected annualized volatility $\left(\sigma_{\mathrm{i}}^{2}\right)^{*}$ & $\begin{array}{c}-0.07 \\
(5.5)\end{array}$ & $\begin{array}{c}-0.07 \\
(5.8)\end{array}$ & $\begin{array}{c}-0.09 \\
(3.3)\end{array}$ \\
\hline Constant & -1.50 & -1.26 & -1.16 \\
\hline Time Dummies & Yes & Yes & Yes \\
\hline N (obs.) & 1,680 & 1,866 & 377 \\
\hline Measure of fit (adj- $\left.R^{2}\right)$ & 0.04 & 0.05 & 0.04 \\
\hline
\end{tabular}

$t$-statistics are in parentheses.

Sample period: July, 2001-October, 2004 in (1) and (2); July, 2001-November, 2001 in (3).

Data quality filter: remove respondents with incomplete replies, those rated as having "poor understanding of questions" or "hostile attitude", and those providing 50/50 replies to all probabilistic questions.

* In (1) - (3) expected volailtity is imputed from Uncertain, under the assumption of asymptotic normality 
Table 8A

Distribution of Imputed Coefficients of Relative Risk Aversion

\begin{tabular}{cccccccc} 
& $\mathrm{N}$ & 10th pct & 25th pct & Median $\gamma$ & 75th pct & 90th pct & Mean $\gamma$ \\
\hline$\gamma$ & 1,986 & 0.0 & 1.9 & 8.1 & 22.6 & 64.7 & 26.2 \\
\hline
\end{tabular}

Data quality filter: remove respondents with incomplete replies, those rated as having "poor understanding of questions" or "hostile attitude", and those providing 50/50 replies to all probabilistic questions.

Table 8B

Imputed Coefficients of Relative Risk Aversion, by expected macro conditions

Better conditions, next

\begin{tabular}{|c|c|c|c|c|}
\hline \multirow[b]{2}{*}{ Expected macro conditions } & \multicolumn{2}{|c|}{12 months } & \multicolumn{2}{|c|}{ Good times 5 years } \\
\hline & $\mathrm{N}$ & $\gamma$ & $\mathrm{N}$ & $\gamma$ \\
\hline Worse / Continuous bad times & 265 & $\begin{array}{c}7.1 \\
{[0.8-19.1]}\end{array}$ & 494 & $\begin{array}{c}5.3 \\
{[0.6-18.6]}\end{array}$ \\
\hline Bad times, qualified & & & 170 & $\begin{array}{c}5.4 \\
{[0.9-19.8]}\end{array}$ \\
\hline Same / Pro-con & 757 & $\begin{array}{c}6.7 \\
{[1.3-19.3]}\end{array}$ & 146 & $\begin{array}{c}7.3 \\
{[1.1-18.5]}\end{array}$ \\
\hline Good times, qualified & & & 175 & $\begin{array}{c}10.5 \\
{[3.0-24.9]}\end{array}$ \\
\hline Better / Continuous good times & 942 & $\begin{array}{c}9.6 \\
{[2.7-26.4]}\end{array}$ & 928 & $\begin{array}{c}9.5 \\
{[2.9-27.4]}\end{array}$ \\
\hline
\end{tabular}

The table presents median estimates of the imputed coefficients of relative risk aversion for each group using equation (3). The inter-quartile range is shown in square brackets. The same data quality filter applies. 
EXACT TIME NOW:

\section{AA5. INTERVIEWER CHECKPOINT:}

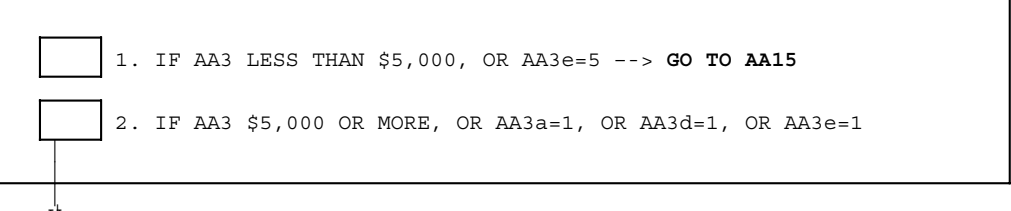

AA5a. Approximately how many years have you (and your family living there) owned stocks or stock mutual funds?

$$
\text { NUMBER OF YEARS }
$$

AA5b. Roughly speaking, what fraction of your (family's) financial assets, including any savings in retirentent plans, is invested in stocks or stock mutual funds

\begin{tabular}{|c|c|c|c|c|}
\hline $\begin{array}{ll}\text { 1. LESS } \\
\text { THAN } \\
\text { A TENTH }\end{array}$ & $\begin{array}{l}\text { 2. BETWEEN A } \\
\text { TENTH AND } \\
\text { A QUARTER }\end{array}$ & $\begin{array}{l}\text { 3. BETWEEN A } \\
\text { QUARTER } \\
\text { AND A HALF }\end{array}$ & $\begin{array}{l}\text { 4. } \text { BETWEEN A } \\
\text { HALF AND } \\
\text { THREE QUARTERS }\end{array}$ & $\begin{array}{l}\text { 5. MORE THAN } \\
\text { THREE } \\
\text { QUARTERS }\end{array}$ \\
\hline
\end{tabular}

AA6. Thinking about the overall rate of return on your (family's) stock investments, including individual stocks and stocks in mutual funds and retirement accounts, can you give a rough guess as to the percentage gain or

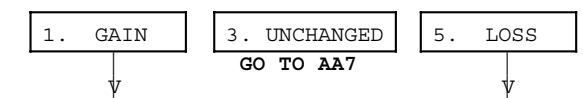

AA6a. (What percentage (gain/loss) would that be for the past twelve months?)

$$
\text { PERCENT GAIN/LOSS }
$$

AA7. Now think about a broadly diversified portfolio of U.S. stocks, such as the S\&P 500. What would you guess was the average annual rate of return earned

$$
\text { PERCENT PER YEAR }
$$

AA8. Now, looking forward, with next month as a starting point, what is the annual rate of return that you would expect a broadly diversified portfolio of U.S. stocks to earn, on average, over the next three years?

PERCENT PER YEAR

AA8a. Would you expect the average return over the next ten to twenty years to be much different than this?
\begin{tabular}{|c|}
\hline $1 . \quad \mathrm{YES}$ \\
$y$
\end{tabular}
\begin{tabular}{|l|}
\hline 5. NO \\
\hline GO TO $\mathrm{AA} 9$
\end{tabular}

AA8b. What annual percentage rate of return would you expect such a stock portfolio to earn, on average, over the next ten to twenty years?

PERCENT PER YEAR

AA9. Since no one knows future stock returns for sure, on a scale of 0 to 100 -where 0 means absolutely no chance, and 100 means absolutely certain -- what do you think the chance is that the average return over the next ten to twenty (AABb/AA8 - 2) and (AABb/AA8 + 2) percent per year?

SCALE 0 TO 100 
AA10. Again, on a scale of 0 to 100, what do you think the chance is that the annual return on this broad portfolio of U.S. stocks will average less than 5 percent
over this ten to twenty year period?

$$
\text { SCALE } O \text { TO } 100
$$

AA11. Now thinking about a shorter horizon, what do you think the chance is that the average annual return on this broad portfolio of U.S. stocks will be less than 5 percent over the next three years?

$$
\text { SCALE } 0 \text { TO } 100
$$

AA12. For the purposes of the next few questions, let's assume that 5 percent is a reasonable expectation for the annual rate of return one can expect low-risk investments,

$$
\begin{aligned}
& \text { 1. YES } \\
& \hline \text { GO TO AA13 }
\end{aligned}
$$

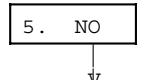

AA12a. What annual rate of return, or interest rate, would you expect these types years?

$$
\text { PERCENT PER YEAR }
$$

AA13. Now, thinking about your ( $f a m i l y ' s$ ) own holdings of stocks, including individual stocks and stocks in mutual funds or retirement accounts, what is ten to twenty years?

PERCENT PER YEAR

\section{AA14. INTERVIEWER CHECKPOINT:}

1. IF AA13 IS LESS THAN OR EQUAL TO 12 PERCENT --> GO TO AA14a

2. IF AA13 IS GREATER THAN 12 PERCENT --> GO TO AA14b
AA14a. Suppose you received persuasive information that the more likely average annual return you could expect over the next ten to twenty years was (AA - 2) percent per year, with some chance that average returns would be higher or lowlting funds into sell some portion of your stock holdings and funds or CDs?

\begin{tabular}{|l|l|}
\hline 1. YES & Y. NO \\
\hline GO TO AA15 & GO TO AA14C
\end{tabular}

AA14b. Suppose you received persuasive information that the more likely average annual return you could expect over the next ten to twenty years was 10 percent per year, with some chance that average returns would be higher or resulting funds into a low-ris

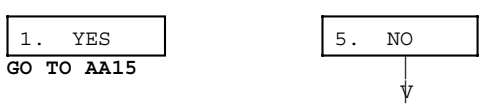

AA14c. How low would your expectation of the next ten to twenty years' rate of your portfolio out of stocks?

\section{PERCENT}

EXACT TIME NOW:

AA15. Although no one can be sure about how the stock market will perform, do you Unink that during the next twelve months stock

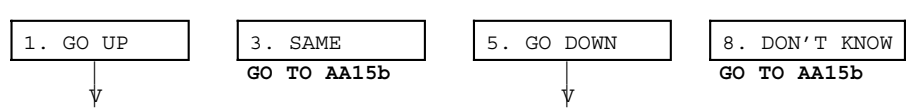

AA15a. By what percent do you expect stock market prices to be PERCENT 

PEXP A3. Now looking ahead--do you think that a year from now you (and your
(106) family living there) will be better off financially, or worse off, or ust about the same as now?
1. WILI
8. D BUS12 A4. Now turning to business conditions in the country as a whole--do you
(108) or bad times, or what?

2. GOOD WITH QUALIFICATIONS

3. PRO-CON

. BAD WITH QUALIFICATIONS

5. $\mathrm{BAD}$
8. $\mathrm{DK}$
9. $\mathrm{NA}$

BAGO A5. Would you say that at the present time business conditions are better or

1. BETTER NOW
3. ABOUT THE SAME

3. ABOUT THE SAM NOW

9. DK

NEWS1 A6. During the last few months, have you heard of any favorable or

NEWS2 unfavorable changes in business conditions?

unfavorable changes in business conditions?

FAVORABLE CHANGES

GOVRNMENT, DERNSE (any reference to defense, code 11 or 12)

10. Recent or upcoming elections; new administration/Congress/

11. More defense/military spending or production; worsening international situation/prospects; acceleration of war/tensions;

2. Less defense/military spending or production; better international prospects; fewer international tensions; less uncertalnty

Specific gover

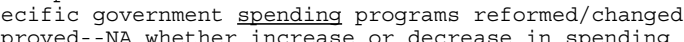

14. Specific government spending programs, begun or increased/ continued (other than defense) (e.g., employment, foreign aid, space, wellare) (incl. programs "modifled "improved"

$\mathrm{SRC} / \mathrm{UM}$

$\underline{\mathrm{VAR} \#}$

BEXP A7. And how about a year from now, do you expect that in the country as .

DORS THE SAME

8. DK

BUS5
(115)

A8. Looking ahead, which would you say is more likely -- that in the country as a whole we'll have continuous good times during the next 5 years or so, or that we will have periods of widespread unemployment or depression, or what?

02. Contimes, qualified (not bad); pretty good, no unemployment, no

03. Pro-con some recession, some unemployment, periods of

4. unemployment
Bad times, qualified (not good); recession; bad at some times but not most of the time; period of widespread unployment; some

05. Bad times, depression; widespread unemployment

DEPENDS (NOT CODEABLE ON SCALE)

ald to allies, international situation

Dorice

trols; tax rebate

11. Depends on other; depends on urban conditions; labor-managemen relations; strikes, labor conditio

torly hopes and wishesi R gives only conparative or relative answer, "Better, " "Same, " "Worse" ; "more/les unemployment or inflation"

A9. As to the economic policy of the government -- I mean steps taken to the government is doing a good job, only fair, or a poor job?

3. ONLY FAIR

5. POOR JOB

8. $\mathrm{DK}$

UNEMP A10. How about people out of work during the coming 12 months -- do you

(117) think that there will be more unemployment than now, about the same,

1. MORE UNEMPLOYMENT

LESS UNEMPLOYMEN

8. DK 